\title{
"Canopy Catalysts" for Alkyne Metathesis: Molybdenum Alkylidyne Complexes with a Tripodal Ligand Framework
}

\section{Journal Article}

Author(s):

Hillenbrand, Julius; Leutzsch, Markus; Yiannakas, Ektoras; Gordon, Christopher (D); Wille, Christian; Nöthling, Nils; Copéret, Christophe iD; Fürstner, Alois

Publication date:

2020-06-24

\section{Permanent link:}

https://doi.org/10.3929/ethz-b-000424374

Rights / license:

Creative Commons Attribution 4.0 International

Originally published in:

Journal of the American Chemical Society 142(25), https://doi.org/10.1021/jacs.0c04742 


\title{
"Canopy Catalysts" for Alkyne Metathesis: Molybdenum Alkylidyne Complexes with a Tripodal Ligand Framework
}

\author{
Julius Hillenbrand, Markus Leutzsch, Ektoras Yiannakas, Christopher P. Gordon, Christian Wille, \\ Nils Nöthling, Christophe Copéret, and Alois Fürstner*
}

Cite This: J. Am. Chem. Soc. 2020, 142, 11279-11294

Read Online

ACCESS 1

Llll Metrics \& More

Article Recommendations

Supporting Information

ABSTRACT: A new family of structurally well-defined molybdenum alkylidyne catalysts for alkyne metathesis, which is distinguished by a tripodal trisilanolate ligand architecture, is presented. Complexes of type 1 combine the virtues of previous generations of silanolate-based catalysts with a significantly improved functional group tolerance. They are easy to prepare on scale; the modularity of the ligand synthesis allows the steric and electronic properties to be fine-tuned and hence the application profile of the catalysts to be optimized. This opportunity is

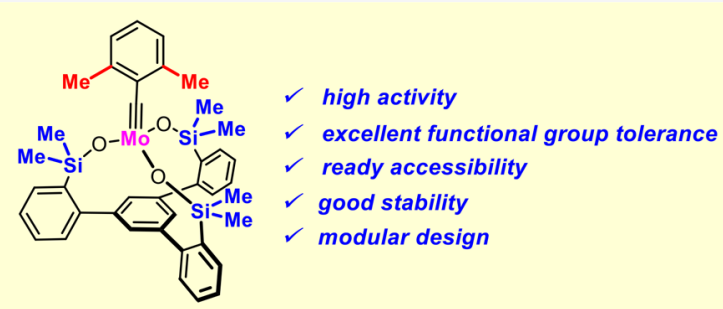
manifested in the development of catalyst $\mathbf{1 f}$, which is as reactive as the best ancestors but exhibits an unrivaled scope. The new catalysts work well in the presence of unprotected alcohols and various other protic groups. The chelate effect entails even a certain stability toward water, which marks a big leap forward in metal alkylidyne chemistry in general. At the same time, they tolerate many donor sites, including basic nitrogen and numerous heterocycles. This aspect is substantiated by applications to polyfunctional (natural) products. A combined spectroscopic, crystallographic, and computational study provides insights into structure and electronic character of complexes of type 1. Particularly informative are a density functional theory (DFT)-based chemical shift tensor analysis of the alkylidyne carbon atom and ${ }^{95} \mathrm{Mo}$ NMR spectroscopy; this analytical tool had been rarely used in organometallic chemistry before but turns out to be a sensitive probe that deserves more attention. The data show that the podand ligands render a Mo-alkylidyne a priori more electrophilic than analogous monodentate triarylsilanols; proper ligand tuning, however, allows the Lewis acidity as well as the steric demand about the central atom to be adjusted to the point that excellent performance of the catalyst is ensured.

\section{INTRODUCTION}

In a recent Communication, we disclosed complex $1 \mathbf{a}$ as the prototype of a new generation of molybdenum alkylidyne complexes, termed "canopy catalysts", for alkyne metathesis because of their distinguishing tripodal silanolate ligand framework (Figure 1). ${ }^{1}$ Shortly after our paper had been published, the Lee group presented its work that had incidentally pursued the same ligand design. ${ }^{2}$

Even though the focus of these two parallel investigations had been somewhat different, both reached the conclusion that such complexes are more than just a tethered variant of catalyst 2a carrying triphenylsilanolate ligands, which had set new standards in the field of alkyne metathesis when it was introduced by our group a decade ago. ${ }^{3-6}$ Outlined below is a comprehensive study into this new family of canopy catalysts, including the optimization of their synthesis, a first ligandtuning exercise, structural investigations, a portrayal of their electronic nature, and new insights into the elementary steps of the catalytic cycle. Most importantly, a focused evaluation of the catalytic performance revealed an unrivaled stability toward numerous basic and protic sites, including unprotected alcohols and even moisture. Overall, this investigation shows that 1a and relatives bear great potential and might well mark a new milestone in the evolution of alkyne metathesis at large. $^{7-10}$

\section{RESULTS AND DISCUSSION}

Design Principles. Complexes 2 and derived bench-stable adducts such as $[\mathbf{2} \cdot($ phen $)]$ (phen $=1,10$-phenanthroline) owe their excellent application profile to the synergy between the operative molybdenum alkylidyne unit $^{11}$ and the ancillary silanolate ligands. ${ }^{3-5}$ Silanolates are weaker $\pi$ - and $\sigma$-donors than ordinary alkoxides ${ }^{12}$ and have "adaptive" ligand properties (Figure 1): ${ }^{3-5}$ bending and stretching of a Mo-O-Si hinge comes with thermal motion at almost no cost. Any such change of the bond angle, however, alters the hybridization of oxygen and hence the degree of $\pi$-donation, which, in turn, gently modulates the energy of the catalyst's frontier orbitals. For this very property, $\mathbf{2}$ is able to meet the opposing electronic optima

Received: April 30, 2020

Published: May 28, 2020 

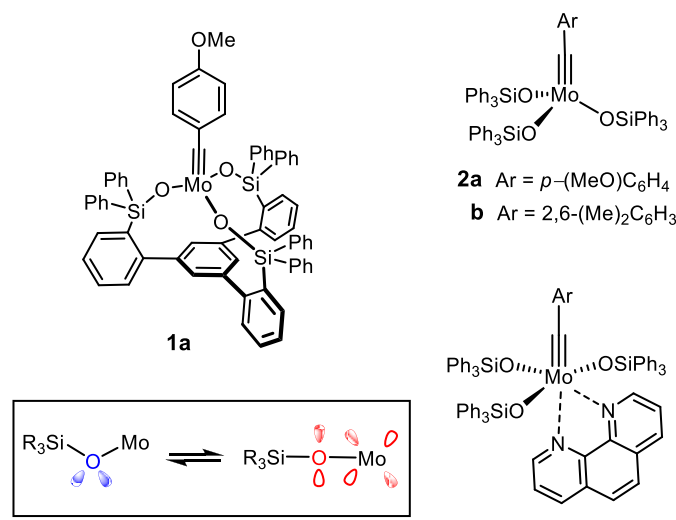

2a $\mathrm{Ar}=p-(\mathrm{MeO}) \mathrm{C}_{6} \mathrm{H}_{4}$

b $\mathrm{Ar}=2,6-(\mathrm{Me})_{2} \mathrm{C}_{6} \mathrm{H}_{3}$

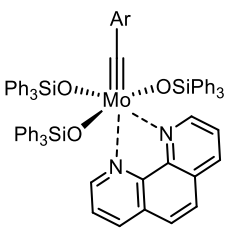

[2.(phen)]

Figure 1. Prototype of the canopy catalysts and the parent triphenylsilanolate complexes; modulation of the donor properties of a silanolate ligand caused by the facile bending and stretching of the $\mathrm{Mo}-\mathrm{O}-\mathrm{Si}$ angle.

of the elementary steps passed through during the catalytic cycle: substrate binding and metallacycle formation are favored by a more Lewis-acidic center, whereas the cycloreversion step and extrusion of the product as the chemically inverse operations have the exact opposite electronic demand. ${ }^{3-5,13,14}$ At the same time, (triaryl)silanolates ${ }^{15}$ are sufficiently bulky to preclude bimolecular decomposition and/or competing associative pathways, preventing alkyne polymerization from occurring. For the longer $\mathrm{O}-\mathrm{Si}$ and $\mathrm{Si}-\mathrm{C}$ bonds, however, the bulk is sufficiently remote from the molybdenum center not to impede substrate binding or product dissociation; only for very hindered alkynes is the size of the silanolates critical. ${ }^{16}$ In that silanolates lower the barriers of all elementary steps and, at the same time, protect the catalyst, they render the overall reaction efficient on electronic and steric grounds. ${ }^{3-7}$

The tempered Lewis acidity that $\mathbf{2 a}$ and relatives draw from the metal/ligand cooperativity also accounts for a remarkable compatibility with functional groups. ${ }^{3-5}$ Numerous applications to complex and/or sensitive target molecules bear ample witness of this fact; ${ }^{17,18}$ an instructive example is shown in Scheme 1. Even certain protic groups are tolerated, ${ }^{19,20}$ although important limitations still remain. This particular problem is challenging: the polarization of a Schrock alkylidyne renders the $\mathrm{C}$ atom of the $[\mathrm{M} \equiv \mathrm{CR}]$ unit innately nucleophilic and basic and hence potentially prone to degradation in a protic environment. ${ }^{11,21}$ Ligand exchange, however, is equally obstructive: any in situ replacement of the silanolates of 2 jeopardizes the virtues of the catalyst and ultimately entails loss of activity. This may explain why 2 usually fails when primary alcohols or related protic sites are present; the comparison shown in Scheme 1 illustrates this paradox.

Under the premise that ligand exchange is detrimental, it seemed reasonable to assume that a chelate structure might improve stability vis-à-vis alcohols and other protic substrates. Our first attempt to reduce this plan to practice met with only partial success (Scheme 2). ${ }^{22}$ Specifically, the trisilanol ligands $\mathbf{4}$ and $\mathbf{5}$ were designed but failed to afford distinct tripodal alkylidyne complexes on reaction with precatalyst 3 . Rather, they lead to partial cross-linking with formation of ill-defined mixtures, which nonetheless show good activity and, as a matter of fact, an improved functional group tolerance compared to $2 .{ }^{22}$ It was with the help of these two-component systems that certain substrates containing primary $-\mathrm{OH}$

Scheme 1. Current State of the Art: Triarylsilanolate Catalysts That Tolerate Diverse Functionality and Complex Settings but Fail with Simple Unhindered Alcohols ${ }^{a}$
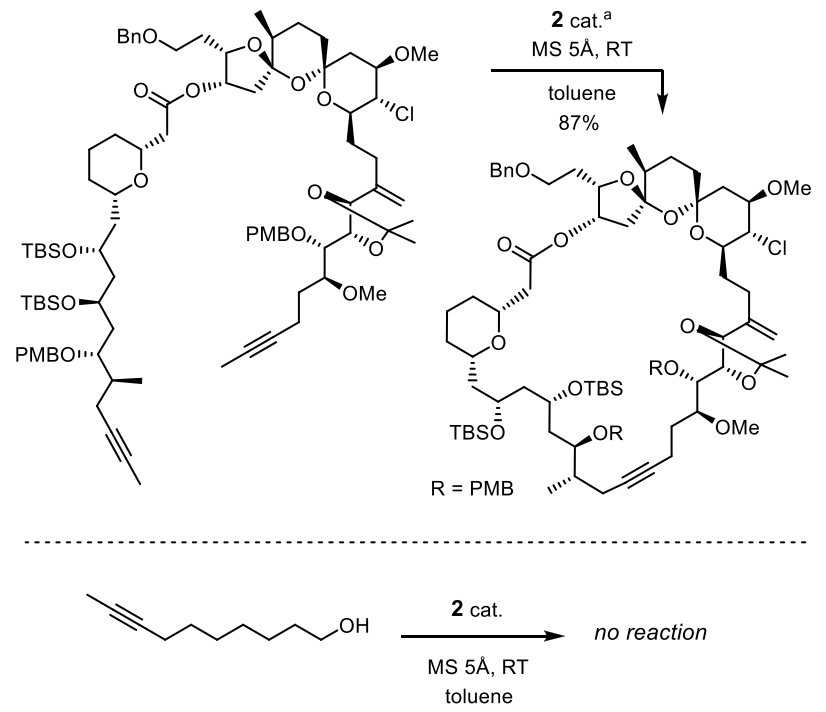

${ }^{a}$ Complex 2 was released in situ from the corresponding ate complex chosen as precatalyst, cf. ref $17 \mathrm{c}$.

Scheme 2. Previous Attempts to Prepare Molybdenum Alkylidyne Complexes with a Podand Ligand Architecture ${ }^{22,23}$
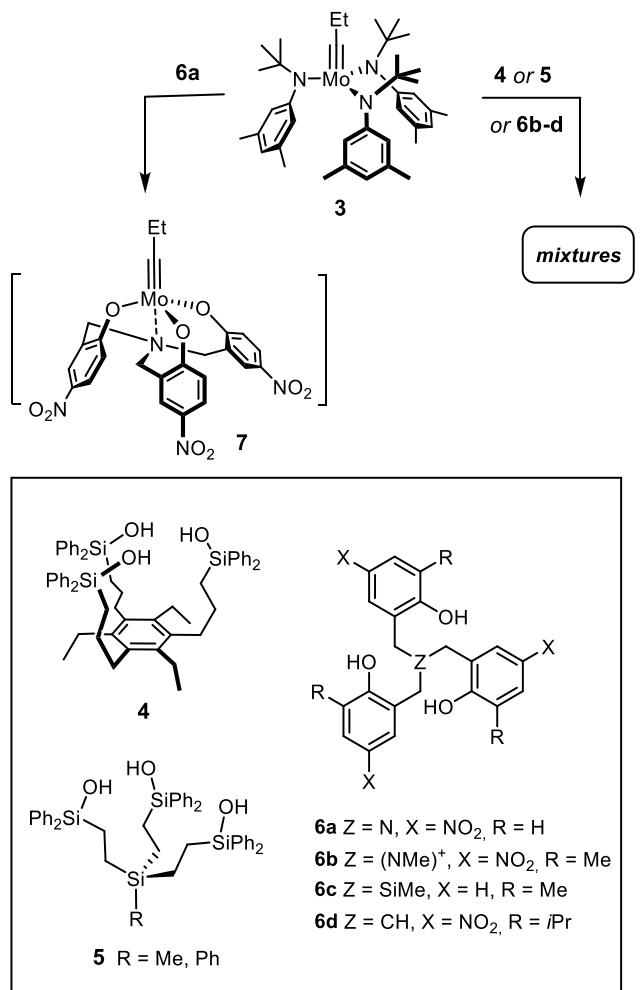

groups could be metathesized for the first time in appreciable yields. $^{22}$

Cross-linking (partial) also seems to plague an alternative ligand scaffold of type 6 composed of tethered phenol units: $^{23-25}$ the only fully characterized podand complex 7 derived from $\mathbf{3}$ and $\mathbf{6 a}$ proved inactive, whereas the 
composition of those mixtures that are catalytically competent is unclear. ${ }^{23}$ In consideration thereof, we were prompted to reassess the design and came up with $\mathbf{1}$ as the prototype of a new generation of catalysts for alkyne metathesis. ${ }^{1,26}$ In a formal sense, the three $\mathrm{Ph}_{3} \mathrm{SiO}-$ groups of the parent complex $\mathbf{2}$ are tied together via an additional phenyl ring that forms the basal plane of a podand ligand framework. In contrast to 4 and 5, the backbone of this new type of tridentate ligand (11) contains only $\mathrm{sp}^{2}$-hybridized $\mathrm{C}$ atoms, which reduces the degrees of conformational freedom and should render the formation of well-defined tripodal complexes more favorable; however, this comes at the cost of increased rigidity, even though we had hoped that the conformationally flexible Mo$\mathrm{O}-\mathrm{Si}$ angle would partly compensate the perceived stiffness of complexes of type 1. It is important to note that each alkyne metathesis catalyst must be able to accommodate different geometries, that is, the tetrahedral ligand environment of the alkylidyne and a trigonal-bipyramidal extreme at the stage of the metallacyclobutadiene intermediate formed upon $[2+2]$ cycloaddition. $^{7-10}$ Provided that this essential geometric boundary condition is met, the modularity of the design should allow the properties of this new catalyst family to be fine-tuned.

Ligand Synthesis and Variation. The preparation of the parent ligand 11a starts off with the cyclocondensation of 2bromoacetophenone to afford tribromide 8a (Scheme 3). ${ }^{27,28}$

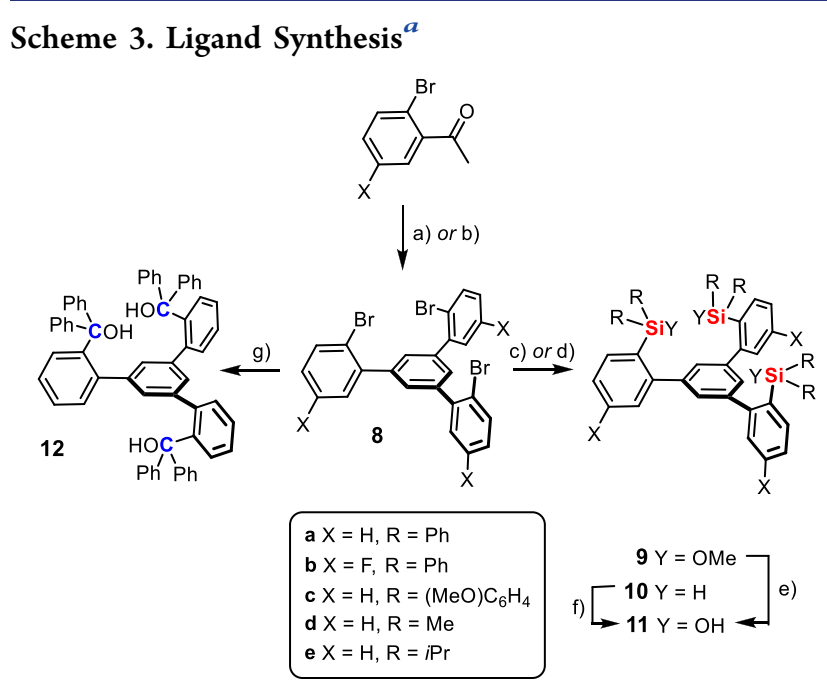

${ }^{a}$ Reagents and conditions: (a) $\mathrm{SiCl}_{4}$, EtOH, $0{ }^{\circ} \mathrm{C} \rightarrow \mathrm{RT}, 90 \%(\mathrm{X}=\mathrm{H}$, $20 \mathrm{~g}$ scale); (b) $\mathrm{TfOH}, 130{ }^{\circ} \mathrm{C}, 55 \%(\mathrm{X}=\mathrm{F})$; (c) $\mathrm{tBuLi}, \mathrm{Et}_{2} \mathrm{O}$, $\mathrm{R}_{2} \mathrm{Si}(\mathrm{OMe})_{2},-125^{\circ} \mathrm{C} \rightarrow \mathrm{RT}, 75 \%(9 \mathrm{a}), 86 \%(9 \mathrm{~b}), 12 \%$ (9c); (d) $t \mathrm{BuLi}, \mathrm{Et}_{2} \mathrm{O}, \mathrm{R}_{2} \mathrm{SiH}(\mathrm{Cl}),-125^{\circ} \mathrm{C} \rightarrow \mathrm{RT}, 91 \%$ (10d), $81 \%$ (10e); (e) aq. $\mathrm{HCl}, 0{ }^{\circ} \mathrm{C} \rightarrow \mathrm{RT}$, quant. (11a, $5 \mathrm{~g}$ scale), $78 \%$ (11b), quant. (11c); (f) $m \mathrm{CPBA}, 94 \%$ (11d in $\left.\mathrm{CH}_{2} \mathrm{Cl}_{2}\right), 81-87 \%$ (11e, in tetrahydrofuran (THF)); (g) $t \mathrm{BuLi}, \mathrm{Et}_{2} \mathrm{O}$, benzophenone, $-125{ }^{\circ} \mathrm{C}$ $\rightarrow$ RT, $78 \%$ (2 g scale).

This reaction was originally performed with triflic acid at elevated temperature but was later found to be much higher yielding upon gentle release of $\mathrm{HCl}$ from $\mathrm{SiCl}_{4}$ and $\mathrm{EtOH}^{29}$ under these conditions, the yield of $\mathbf{8 a}$ increased from $55 \%$ to $90 \%$ on a $20 \mathrm{~g}$ scale. Exhaustive metal/halogen exchange with excess $t \mathrm{BuLi}$ in $\mathrm{Et}_{2} \mathrm{O}$ followed by quenching of the resulting triorganolithium intermediate with $\mathrm{Ph}_{2} \mathrm{Si}(\mathrm{OMe})_{2}$ works nicely (75\%, $4 \mathrm{~g}$ scale), provided that the metalation step is performed at very low temperature $\left(-125^{\circ} \mathrm{C}\right) .{ }^{30}$ The final hydrolysis proceeds quantitatively on treatment of 9a with aqueous $\mathrm{HCl}$ ( $5 \mathrm{~g}$ scale). Trisilanol 11a is thus available in multigram quantity in three high-yielding steps.

Because this route is modular, it provides ready access to analogues as necessary for catalyst screening and optimization. To this end, compound $\mathbf{1} 1 \mathbf{b}^{28}$ bearing a fluorine substituent on the three arenes forming the fence was prepared in good yield. Additional compounds were made to study the influence of the substituents on silicon: quenching of the triorganolithium species derived from $8 \mathrm{a}$ with $\left(\mathrm{MeOC}_{6} \mathrm{H}_{4}\right)_{2} \mathrm{Si}(\mathrm{OMe})_{2}$ followed by hydrolysis gave $11 \mathrm{c}$. Although this reaction was less clean, ${ }^{31}$ a sufficient amount was secured (ca. $400 \mathrm{mg}$ ) to study the properties of this particular ligand. For the preparation of $11 \mathrm{~d}, \mathrm{e}$ with two aliphatic substituents on silicon, it was best to use $\mathrm{R}_{2} \mathrm{Si}(\mathrm{H}) \mathrm{Cl}(\mathrm{R}=\mathrm{Me}, i \mathrm{Pr})$ as the electrophilic partner; oxidative cleavage of the $\mathrm{Si}-\mathrm{H}$ bond in $\mathbf{1 0}$ with metachloroperoxybenzoic acid ( $m$ CPBA) furnished the desired compounds. Even though silanols are privileged ligands for molybdenum alkylidynes, ${ }^{3-7}$ we also prepared the carbinol analogue $\mathbf{1 2}$ for comparison by lithiation of $\mathbf{8 a}$ followed by a benzophenone quench (Scheme 3$)^{26}$

In the solid state, the trisilanol ligands $11 \mathbf{a},{ }^{1} \mathbf{1 1 b},^{28} \mathbf{1 1} \mathbf{c}^{28}$ and 11e (Figure 2) invariably adopt a conformation in which

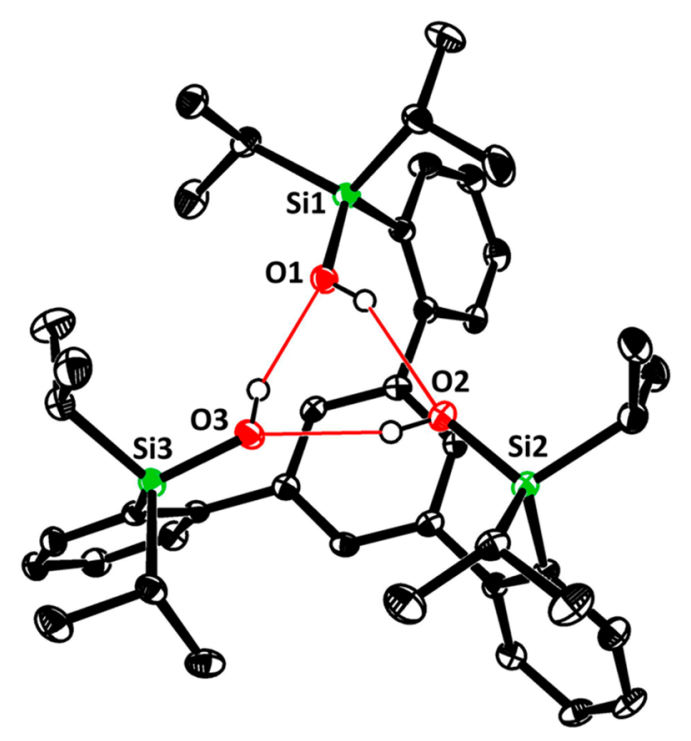

Figure 2. Structure of compound 11e in the solid state (only one of the two independent molecules in the unit cell is shown). Hydrogen atoms except for the $-\mathrm{OH}$ protons are not shown for clarity. The red lines indicate hydrogen bonds.

the three $\mathrm{Si}-\mathrm{OH}$ groups are upward/inward-oriented as a consequence of a cyclic array of hydrogen bonds between the individual $-\mathrm{Si}-\mathrm{OH}$ units. This favorable approximate $C_{3}$ symmetry, as necessary for the formation of the targeted podand complexes, is maintained in solution, as evident from the NMR spectra. The situation is very different for the carbinol analogue 12 (Figure 3): one pair of reciprocal $\mathrm{H}$ bonds connects only two of the alcohol groups, whereas the third $-\mathrm{OH}$ is oriented to the opposite side of the basal plane. Although line broadening in the NMR spectra indicates that the system is dynamic at RT, the two-up/one-down geometry is the average conformation of $\mathbf{1 2}$ in solution that gets increasingly locked upon cooling (see the Supporting Information). 


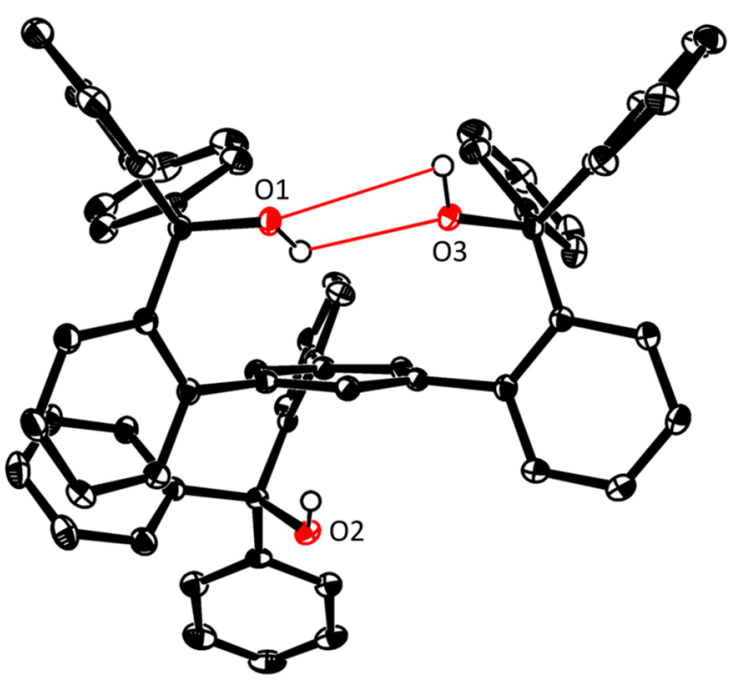

Figure 3. Structure of compound $\mathbf{1 2}$ in the solid state. Cocrystallized $\mathrm{CH}_{2} \mathrm{Cl}_{2}$ and hydrogen atoms (except for the $-\mathrm{OH}$ protons) are not shown for clarity. The red lines indicate hydrogen bonds.

Preparation of the Podand Complexes and the Aggregation Issue. The parent complex $2 \mathrm{a}$ is formed from the tribromoalkylidyne complex 13a by salt metathesis with $\mathrm{Ph}_{3} \mathrm{SiOM}(\mathrm{M}=\mathrm{K}, \mathrm{Na}) .{ }^{1,3,4}$ However, this method was not deemed ideal for the preparation of the podand complexes of type 1 for the following reasons: (i) The conformation of trisilanols 11 is perfect for the envisaged podand complex formation; deprotonation almost certainly enforces an unfavorable change because charge repulsion destabilizes the upward/inward orientation of the $\mathrm{Si}-\mathrm{O}$ vectors held together in 11 by hydrogen bonding. (ii) Any such conformational change, however, increases the likelihood of cross-linking. The resulting ill-defined products cannot convert to the targeted podand complex because salt metathesis is irreversible; a reduced yield of $\mathbf{1}$ is the likely consequence. ${ }^{32}$ (iii) The poor solubility of the trisodium (potassium) salts of $\mathbf{1 1}$ in aprotic organic media is a handicap in practical terms. ${ }^{33}$

The use of the molybdenum complex 3 bearing moderately basic amide ligands would probably allow these issues to be avoided. It has already been shown to undergo ligand exchange with our first-generation trisilanole ligands 4 and 5 (see Scheme 2). ${ }^{22}$ Yet, we sought a more practical solution because 3 is exceptionally sensitive, requiring rigorously anhydrous conditions and an $\operatorname{Ar}\left(\right.$ not $\mathrm{N}_{2}$ !) atmosphere. ${ }^{34}$ A convenient alternative was found in complexes 14, which themselves are catalytically inactive but fairly easy to make (Scheme 4). Because tert-butoxy groups are more basic than a silanole, it suffices to stir a solution of 11a and 14a in toluene at ambient temperature to achieve quantitative ligand exchange; moreover, the reaction is entropically favorable. ${ }^{35}$ The released tertbutanol can be evaporated in high vacuum, which makes the isolation of the resulting bright-yellow and only moderately airsensitive complex $[\mathbf{1 a}]_{2}$ straightforward. The analogous reaction of the all-carbon analogue $\mathbf{1 2} \mathrm{did}$ not afford a podand complex (Scheme 5). Rather, the peculiar conformation of the ligand translates into the structure of the resulting complex 16: two tert-butoxide ligands of $14 a$ were replaced by 12 , which acts as a bidentate rather than tridentate ligand, and the third tert-alcohol unit is dangling and fails to substitute the remaining tert-butoxide even at elevated temperature (see the Supporting Information). Complex 16 showed only marginal
Scheme 4. Preparation of the Catalysts ${ }^{a}$

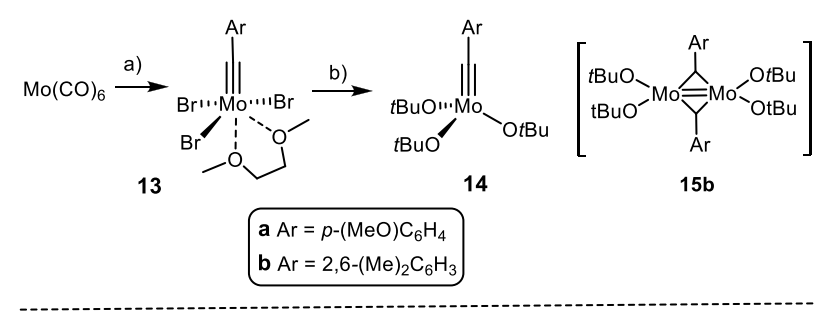

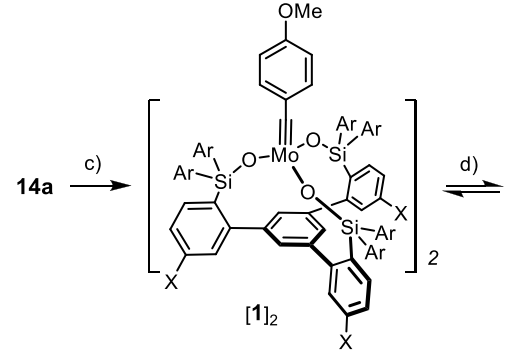

a $X=\mathrm{H}, \mathrm{Ar}=\mathrm{Ph}$
b $X=\mathrm{F}, \mathrm{Ar}=\mathrm{Ph}$
c X $=\mathrm{H}, \mathrm{Ar}=(\mathrm{MeO}) \mathrm{C}_{6} \mathrm{H}_{4}$
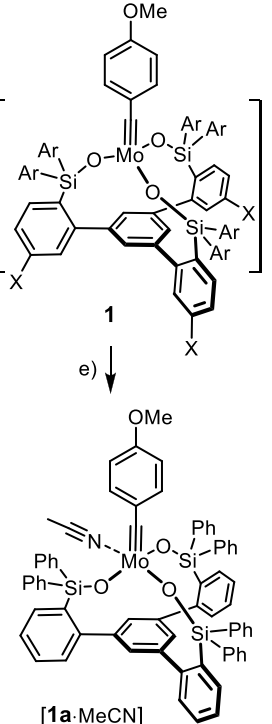

${ }^{a}$ Reagents and conditions: (a) see ref 4; (b) $\mathrm{NaO} t \mathrm{Bu}, \mathrm{THF}, 83 \%$; (c) 11, toluene, $95 \%\left([\mathbf{1 a}]_{2}\right), 50 \%\left([\mathbf{1 b}]_{2}, 76 \%\left([\mathbf{1 c}]_{2}\right) ;(\mathrm{d})\right.$ toluene, 60 ${ }^{\circ} \mathrm{C}$, see text; (e) MeCN, quant. (NMR), see text.

\section{Scheme 5. Carbinol Variant}

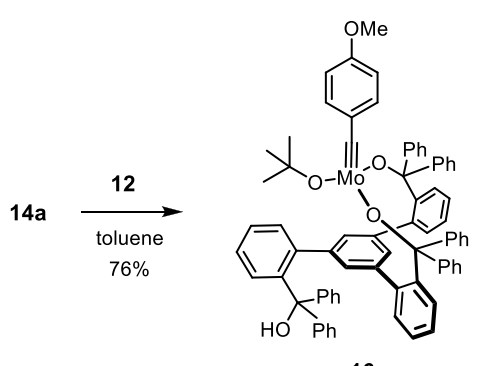

16

activity in the test reaction chosen to benchmark the new catalysts (see below); however, it is reminiscent of a catalyst for applications in material science that had been deliberately designed to exhibit a tempered character. ${ }^{36,37}$

As previously described, the new podand complex $[1 \mathbf{a}]_{2}$ is a supramolecular aggregate that dissociates quantitatively in toluene solution at $60{ }^{\circ} \mathrm{C}$ to give the desired monomeric species $1 \mathrm{a} ;{ }^{1}$ once formed, the monomer persists for extended periods of time ( $\gg 7$ days at RT (NMR); see the Supporting Information) and shows excellent thermal stability ( $\gg 12 \mathrm{~h}$ in $\left[\mathrm{D}_{8}\right]$-toluene at $60{ }^{\circ} \mathrm{C}$; see the Supporting Information). However, monomeric $1 \mathrm{la}$ reverts to the dimeric aggregate $[\mathbf{1 a}]_{2}$ upon evaporation of the solvent or on cooling; complexes $\mathbf{1 b}, \mathbf{c}$ show the same behavior. The acetonitrile adduct $[\mathbf{1} \mathbf{a} \cdot \mathrm{MeCN}]$, in contrast, remains monomeric in the solid state: it was in this format that we were originally able to prove the podand ligand 
architecture about the molybdenum alkylidyne unit by X-ray crystallography. ${ }^{1}$

Although this aggregation in the solid state does not preclude alkyne metathesis from occurring, ${ }^{1}$ the rather poor solubility of $[\mathbf{1 a}]_{2}$ and the need to disassemble this aggregate via ligation and/or heating are not ideal for applications in catalysis. Because crystals of $[1]_{2}$ suitable for X-ray diffraction could not be grown, indirect evidence had to guide our efforts to improve the design with the aim of avoiding such complications. To this end, we revisited the structure of the parent complex 2a, which is also a dimeric aggregate in the solid state as well as in concentrated solution. Upon dilution, however-that is, under conditions typically used for ringclosing alkyne metathesis $(\mathrm{RCAM})^{38}-[\mathbf{2 a}]_{2}$ fully dissociates to the monomeric complex 2a (DOSY; see the Supporting Information). The X-ray structure (Figure 4$)^{4}$ shows that the

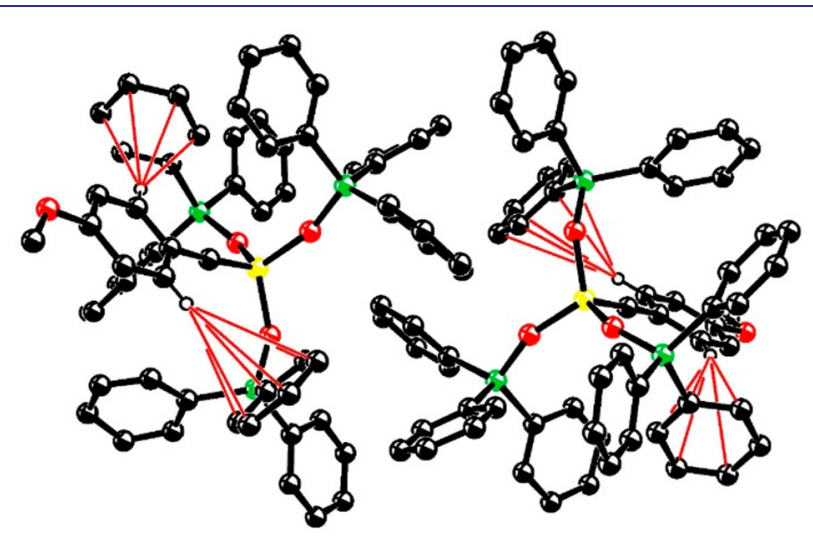

Figure 4. Structure of complex of $[\mathbf{2 a}]_{2}$ in the unit cell. All $\mathrm{H}$ atoms except for the ortho-protons of the benzylidyne units are omitted for clarity. The red lines indicate the close interactions of these $\mathrm{H}$ atoms with neighboring phenyl rings of the silanolate ligands, indicative of $\mathrm{C}-\mathrm{H} / \pi$ interactions. The packing reveals numerous intermolecular $\pi / \pi$ and $\mathrm{C}-\mathrm{H} / \pi$ interactions between the two independent molecules of this dimeric aggregate. Color code: $\mathrm{Mo}=$ yellow, $\mathrm{O}=$ red, $\mathrm{Si}=$ green, and $\mathrm{C}=$ black.

ortho-H atoms of each benzylidyne unit of $[\mathbf{2 a}]_{2}$ are engaged in tight $\mathrm{C}-\mathrm{H} / \pi$ interactions with neighboring phenyl groups of the silanolate ligands; the latter, in turn, experience numerous intermolecular $\mathrm{C}-\mathrm{H} / \pi$ and $\pi / \pi$ interactions ${ }^{39}$ with the phenyl rings of the second independent molecule in the unit cell. We suppose that $[\mathbf{1 a}]_{2}$ is the result of analogous noncovalent interactions: ${ }^{40}$ supramolecular aggregate formation is hence likely a consequence of the multitude of fairly preorganized arene rings in the first ligand sphere about the molybdenum center.

On the basis of this analysis, we envisaged two different ways to prevent supramolecular aggregate formation. Under the proviso that the $\mathrm{C}-\mathrm{H} / \pi$-contact of the ortho-benzylidyne protons instigates a network of tight intermolecular interactions, it may suffice to put ortho-substituents on the benzylidyne unit to break the contacts. ${ }^{41,42}$ The second conceivable design was the replacement of the phenyl groups responsible for the intermolecular contacts altogether by appropriate alkyl substituents. ${ }^{15}$

In pursuit of these ideas, the 2,6-dimethylbenzylidyne complex 1e was prepared from $14 \mathbf{b}^{4,35}$ by the route outlined above (Scheme 6). In line with our expectation, $1 \mathbf{e}$ is indeed monomeric in the solid state (Figure 5) as well as in solution
Scheme 6. Additional Catalysts ${ }^{a}$
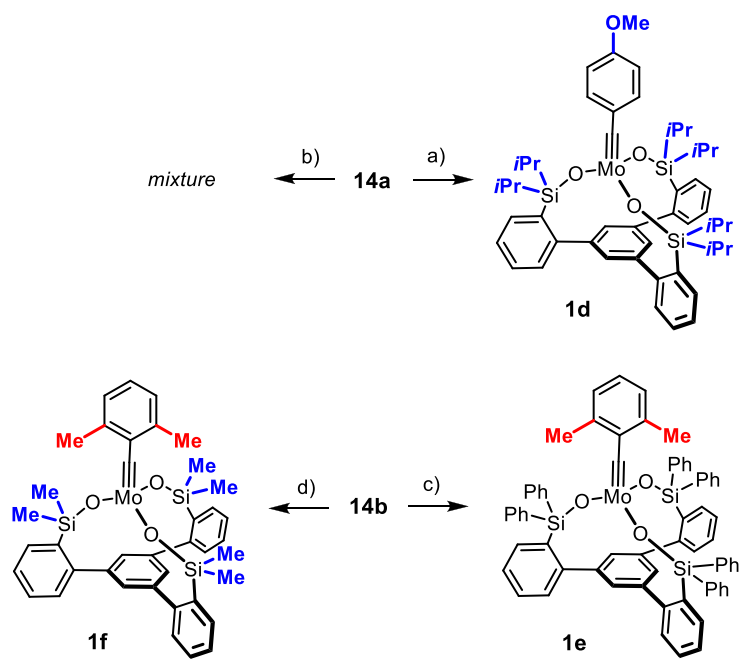

${ }^{a}$ Reagents and conditions: (a) 11e, toluene, 99\%; (b) 11d, toluene; (c) 11a, toluene, $65 \%$; (d) $11 \mathrm{~d}$, toluene, $84 \%$.

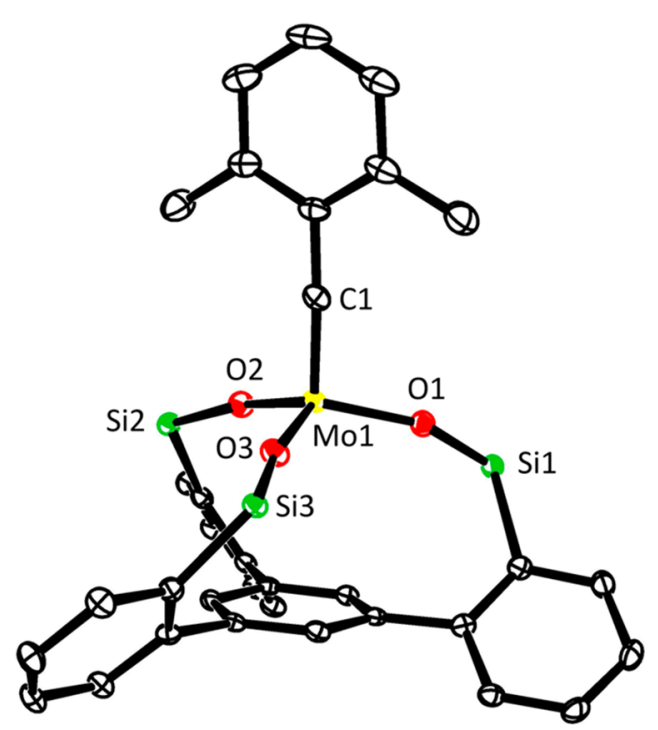

Figure 5. Representation of the truncated structure of complex 1e in the solid state, in which the lateral phenyl rings on silicon were removed to unveil the almost linear benzylidyne unit and the compressed array of the core, which clearly deviates from an ideal tetrahedral geometry; see text. Hydrogen atoms are omitted for clarity. For the full structure, see the Supporting Information.

(DOSY; see the Supporting Information). The same is true for complexes 1d and 1f carrying two aliphatic substituents on the silicon bridges: both of them are monomeric in solution (see the Supporting Information), even though $1 \mathbf{d}$ retains the $p$ methoxybenzylidyne group. The X-ray structure of 1d (Figure 6) contains two independent molecules in the unit cell, but they do not entertain any short intermolecular contacts between them (see the Supporting Information).

It is important to note that the reaction of the slimmest ligand 11d with 14b carrying an encumbered 2,6-dimethylbenzylidyne unit afforded the expected podand complex If together with a small amount of an organometallic impurity, which also contains an alkylidyne (see the Supporting Information). The analogous reaction of $11 \mathrm{~d}$ with $14 \mathrm{a}$ bearing a $p$-methoxybenzylidyne, in contrast, furnished an ill-defined 


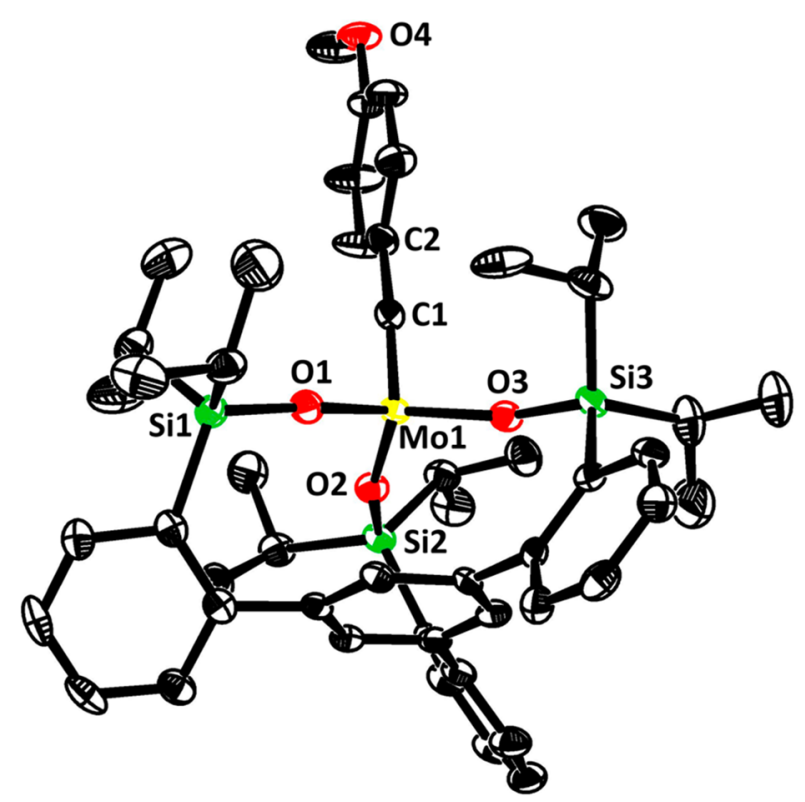

Figure 6. Structure of complex $1 \mathbf{d}$ in the solid state. Hydrogen atoms are omitted for clarity.

mixture that was not analyzed any further (Scheme 6). These observations suggest that an adequate steric balance between the size of the alkylidyne and the steric demand of the periphery is necessary to prevent (partial) cross-linking from occurring.

Structural Aspects and Electronic Implications. The structures of $\mathbf{1 d}, \mathbf{1 e}$, and $[\mathbf{1 a} \cdot \mathrm{MeCN}]^{1}$ in the solid state verify the tripodal silanolate ligand architecture capping the coordination site trans to the alkylidyne. While the lengths of the Mol $\equiv \mathrm{C} 1$ bonds $(1.742(2) \AA$ in $1 \mathrm{e} ; 1.741(5) \AA$ in $1 \mathrm{~d})$ fall into the expected range, ${ }^{3,4}$ the alkylidyne units Mo1 $\equiv \mathrm{C} 1-$ $\mathrm{C} 2$ of these complexes are almost linear, with bond angles of $177.1(2)^{\circ}$ and $176.2(4)^{\circ}$, respectively. For comparison, the alkylidyne of $\mathbf{2} \mathbf{b}$ has a bond angle of only $171.4(2)^{\circ} .4$ Therefore, we believe that the linearity in $\mathbf{1 d}$ and $\mathbf{1 e}$ is significant rather than incidental. ${ }^{43}$ Such a linear array leads to optimal orbital overlap between the Mol $\equiv \mathrm{C} 1$ unit and the arene and explains the rather short $\mathrm{C} 1-\mathrm{C} 2$ bond (1.448(3) $\AA$ in 1e). In line with this notion, the computed lowest unoccupied molecular orbital (LUMO) is indeed delocalized over the entire benzylidyne unit, with strong lobes on the 2,6dimethylphenyl ring (Figure 7).

The bond angles merit detailed consideration. For the canopy catalyst 1e, the $\mathrm{Mo}-\mathrm{O}-\mathrm{Si}$ bond angles are $156.2(1)^{\circ}$, $164.4(1)^{\circ}$, and $170.6(2)^{\circ}$, whereas its monodentate cousin $2 b$ shows $146.4(1)^{\circ}, 154.1(1)^{\circ}$, and $169.4(1)^{\circ} .{ }^{4}$ The corresponding bond angles in $\mathbf{1 d}$ are fairly uniform $\left(160.9(2)^{\circ}, 161.3(2)^{\circ}\right.$, $165(2)^{\circ}$ ) but again more obtuse on average than that of $2 \mathbf{b}$. As a consequence of this stretching in the periphery, the ligand sphere about the Mo center in $\mathbf{1 d}$ and $\mathbf{1 e}$ notably deviates from an ideal tetrahedral geometry (Figure 5). This fact is also manifested in the significantly reduced $\mathrm{C} 1-\mathrm{Mol}-\mathrm{O}$ bond angles $\left(102.6(1)^{\circ}, 103.2(1)^{\circ}, 103.4(1)^{\circ}\right.$ in $1 \mathbf{e}$; ideal tetrahedron: $\left.109.47^{\circ}\right)$. Although the Mo center resides above the plane defined by the three O atoms $(0.42 \AA)$, the elevation is smaller than in the parent complex $2 \mathbf{b}(0.49 \AA)$.

The Mo atom of $1 \mathrm{e}$ is located $3.52 \AA$ above the centroid of the phenyl ring that forms the basal plane of the tripodal framework. At first sight, this situation resembles a largely

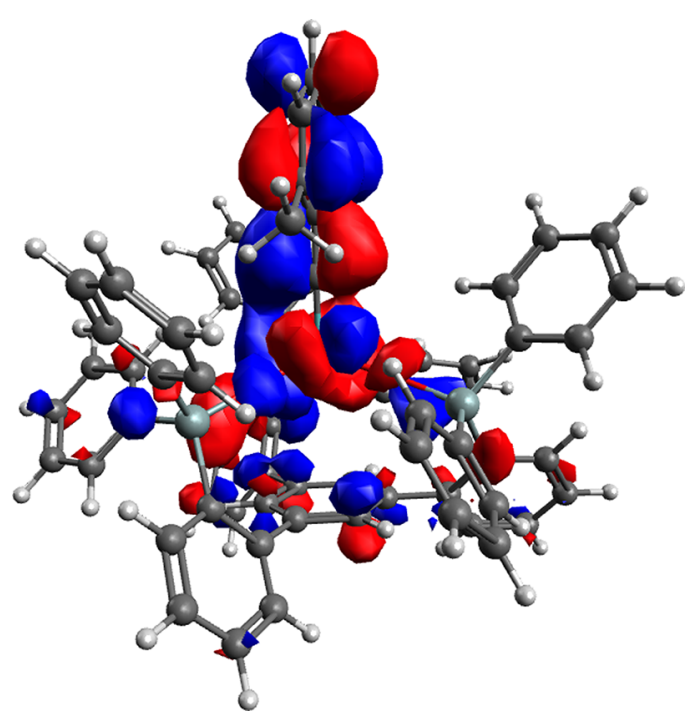

Figure 7. LUMO of complex 1e.

electrostatic cation $/ \pi$ interaction ${ }^{39}$ but is likely more involved; the fact that the LUMO shows small but distinct lobes on the basal phenyl group (Figure 7) indicates a weak but nonnegligible through-space orbital interaction. ${ }^{44}$ This aspect is subject to further investigations.

${ }^{95}$ Mo NMR Study. The structures of $1 d, 1 e$, and [1a. $\mathrm{MeCN}]^{1}$ in the solid state provide only a static picture, but the observed geometric attributes of the complexes have important electronic implications as they impact on the hydridization of the $\mathrm{O}$ atoms and on the orbital overlap. Therefore, a more detailed investigation into the electronic character of the new catalysts in solution seemed warranted.

As a spin $5 / 2$ nucleus with low natural abundance (ca. $15.9 \%$ ), a low gyromagnetic ratio, but a rather low quadrupole moment, the ${ }^{95} \mathrm{Mo}$ isotope has only rarely been used for analytical purposes in organometallic chemistry. ${ }^{45} \mathrm{We}$ are aware of a single investigation into molybdenum alkylidynes, ${ }^{46}$ which reports the ${ }^{95} \mathrm{Mo} \mathrm{NMR}$ shifts of $\left[\left(\mathrm{Me}_{3} \mathrm{SiCH}_{2}\right)_{3^{-}}\right.$$\left.\mathrm{Mo} \equiv \mathrm{CSiMe}_{3}\right]$ and $\left[\left(\mathrm{Me}_{3} \mathrm{CCH}_{2}\right)_{3} \mathrm{Mo} \equiv \mathrm{CCMe}_{3}\right]^{47}$ but failed to record the signal of $\left[(t \mathrm{BuO})_{3} \mathrm{Mo} \equiv \mathrm{CPh}\right]$; all three complexes are catalytically incompetent.

Despite this only partly encouraging precedent, we found this technique very useful in the present context. Good ${ }^{95} \mathrm{Mo}$ NMR spectra of a representative set of complexes were obtained in $\left[\mathrm{D}_{8}\right]$-toluene at $60{ }^{\circ} \mathrm{C}$. Quadrupolar relaxation is slower at higher temperature and hence the lines are sharper; ${ }^{48}$ at the same time, all complexes are monomeric in solution under these conditions. A well-resolved signal at $\delta_{\mathrm{Mo}}=79.6$ $\mathrm{ppm}$ was recorded for $\left[(t \mathrm{BuO})_{3} \mathrm{Mo} \equiv \mathrm{CAr}\right](14 \mathrm{a}, \mathrm{Ar}=p$ $\mathrm{MeOC}_{6} \mathrm{H}_{4}$ ) (see the Supporting Information); this complex is a close relative of $\left[(t \mathrm{BuO})_{3} \mathrm{Mo} \equiv \mathrm{CPh}\right]$, which had defied detection in the only prior study. ${ }^{46}$ While $\mathbf{1 4 a}$ itself is catalytically inactive, it serves as the starting point for the preparation of the canopy catalysts (see Schemes 4 and 6).

For the lack of pertinent literature data, it is currently impossible to construe the recorded shifts by comparison with reference compounds. However, we are inclined to believe that the ${ }^{95} \mathrm{Mo}$ shifts reflect changes in the electronic character of these complexes quite closely. Figure 8 compares the spectra of $\mathbf{1 a}$ and $\mathbf{1 e}$, which carry the identical tripodal ligand but differ in the substitution of the benzylidyne. Although quite remote, the change from the $p-\mathrm{MeO}$ group in 1a to the 2,6-dimethyl 


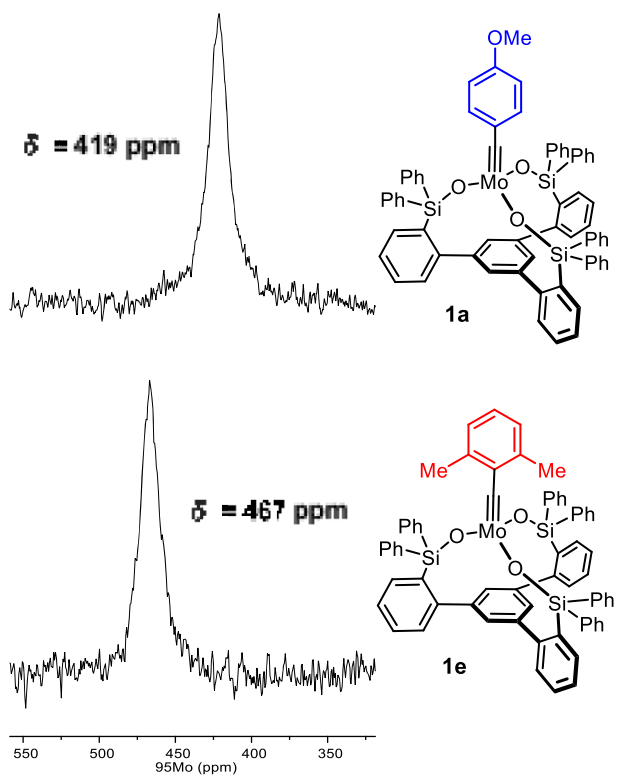

Figure 8. ${ }^{95}$ Mo NMR spectra of the monomeric canopy complexes 1a and 1e differing only in the aryl substituent on the alkylidyne. The spectra were recorded at $60{ }^{\circ} \mathrm{C}$.

substitution pattern in 1e entails notable deshielding. This fact proves that the Mo-alkylidyne is effectively coupled to the $\pi$ system of the arene: as a good donor substituent, the $\mathrm{MeO}-$ group imparts higher electron density onto the Mo center, which the spectral response seems to mirror.

To further probe this aspect, an additional series of complexes was analyzed. For the sake of direct comparison, all of them carried the $p$-methoxybenzylidyne group (Figure 9) but differ in the silanolate ligands; any electronic communication with the Mo center is now mediated via the $\mathrm{O}$ bridge. The electron-withdrawing fluorides in $\mathbf{1 b}$ cause deshielding relative to the parent compound $1 \mathrm{a}$, whereas the two $\mathrm{MeO}$ groups in 1c entail a small but significant shift to higher frequencies. As expected, the more drastic electronic change upon formal replacement of the aryl groups on silicon by more electron-releasing isopropyl substituents in 1d causes a more pronounced effect in the same direction. ${ }^{49}$ Equally indicative is the finding that $\left[(t \mathrm{BuO})_{3} \mathrm{Mo} \equiv \mathrm{CAr}\right]\left(\mathbf{1 4 a}, \mathrm{Ar}=p-\mathrm{MeOC}_{6} \mathrm{H}_{4}\right)$ $\left(\delta_{\mathrm{Mo}}=79.6 \mathrm{ppm}\right)$ resonates at much higher field (see the Supporting Information), reflecting the fact that tertiary carbinol ligands are better donors than silanols. ${ }^{12}$

The trend observed in the ${ }^{95} \mathrm{Mo}$ spectra finds correspondence in the ${ }^{13} \mathrm{C}$ as well as ${ }^{29} \mathrm{Si}$ NMR shifts (Table 1 ); the only exception is the alkylidyne $\mathrm{C}$ signal of $\mathbf{2 a}$, but this complex has a different ligand set. Although caution has to be exerted, it is tempting to see a qualitative correlation between these spectral data with the electron density and hence Lewis acidity of the metal center. Under this proviso, the new complex 1a is more Lewis acidic than the parent complex 2a, even though the rather obtuse $\mathrm{Mo}-\mathrm{O}-\mathrm{Si}$ angles would suggest otherwise. The influence of the bond angles seems to be outweighed by the distortion of the first coordination sphere about the $\mathrm{Mo}(+6)$ center and the particular structural features of the tripodal ligand framework.

Chemical Shift Tensor Analysis. The qualitative conclusion that the molybdenum alkylidyne unit of the canopy catalyst $1 \mathbf{e}$ is slightly more Lewis acidic than that of its cousins 2b containing monodentate triarylsilanolate ligands can be
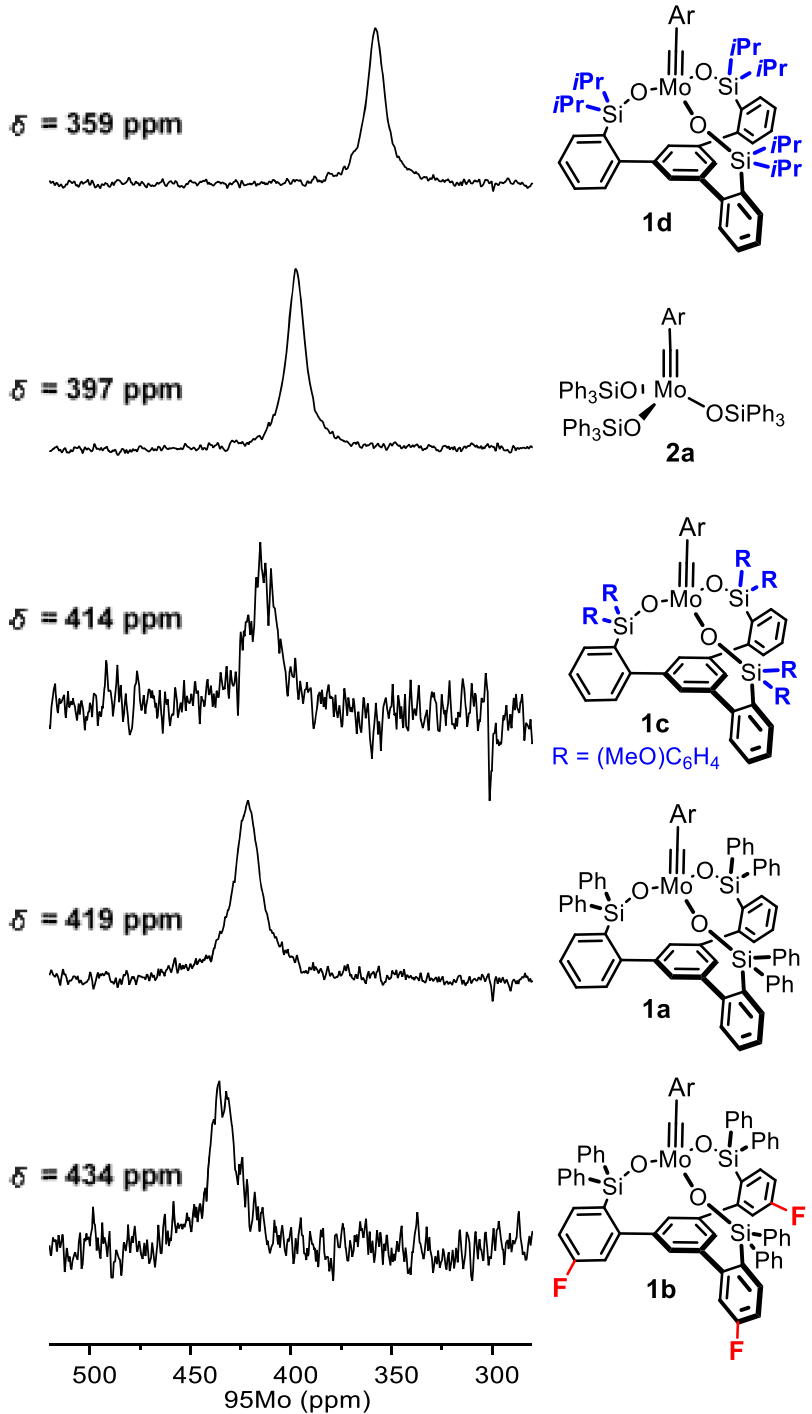

Figure 9. ${ }^{95}$ Mo NMR spectra of different complexes (all in monomeric form) bearing the same aryl substituent on the alkylidyne. All spectra were recorded at $60{ }^{\circ} \mathrm{C}$; $\mathrm{Ar}=p-\mathrm{MeOC}_{6} \mathrm{H}_{4}$.

Table 1. Relevant ${ }^{95} \mathrm{Mo},{ }^{29} \mathrm{Si}$, and ${ }^{13} \mathrm{C}$ NMR Shifts ([D $\left.{ }_{8}\right]$ Toluene, ppm) of Molybdenum $p$-Methoxybenzylidyne Complexes Bearing Different Silanolate Ligands

\begin{tabular}{cccc} 
complex & ${ }^{95} \mathrm{Mo}(\delta)$ & ${ }^{29} \mathrm{Si}(\delta)$ & ${ }^{13} \mathrm{C}(\delta)$ \\
\hline $\mathbf{1 d}$ & 358 & +10.2 & 303.3 \\
$\mathbf{2 a}$ & 397 & -8.0 & 300.5 \\
$\mathbf{1 c}$ & 414 & -9.1 & 309.3 \\
$\mathbf{1 a}$ & 419 & -9.9 & 310.4 \\
$\mathbf{1 b}$ & 434 & -9.8 & 311.4 \\
\hline
\end{tabular}

probed in greater detail by chemical shift tensor (CST) analysis of the alkylidyne carbon atom. ${ }^{50}$ This approach is particularly appealing as the relation between the ${ }^{13} \mathrm{C}$ chemical shift and the molecular electronic structure of transition metal complexes is fairly well-explored ${ }^{51}$ and has been used to gain information on the electronic properties of metal alkylidynes and related complexes. ${ }^{13,52}$

Chemical shift is an anisotropic property that can be described by the three principal components of the chemical shift tensor $\left(\left(\delta_{\text {iso }}=\left(\delta_{11}+\delta_{22}+\delta_{33}\right) / 3\right)\right.$. The property 
calculated by ab initio methods is the shielding tensor $\sigma\left(\delta_{\mathrm{ii}} \approx\right.$ $\left.\sigma_{\text {iso,ref }}-\sigma_{\text {ii }}\right)$, which can be deconvoluted into diamagnetic and paramagnetic terms $\left(\sigma=\sigma_{\text {dia }}+\sigma_{\text {para }}\right)$ : while diamagnetic terms mainly arise from core orbitals and are hence quite insensitive to the electronic environment, the paramagnetic contributions are sensitive to frontier orbitals as they arise from the magnetically induced admixture of electronically excited states into the electronic ground state via the angular momentum operator $L_{i}$. This relation between chemical shift and molecular electronic structure makes chemical shift one of the few molecular descriptors that are sensitive to the anisotropy of the electronic structure around a nucleus. In a pictorial view, strong deshielding of a given nucleus occurs along a direction $i$ if a high-lying occupied orbital on this nucleus can be superimposed onto a low-lying vacant orbital on the same nucleus by rotation along the axis $i$. Importantly, this deshielding is expected to increase for a decreasing energy gap between the involved orbitals and is hence often indicative of reactive frontier orbitals (i.e., high-lying highest occupied molecular orbital (HOMO) and/or low-lying LUMO).

The three most relevant orbital couplings for a metal alkylidyne are schematically shown in Figure 10: a previous

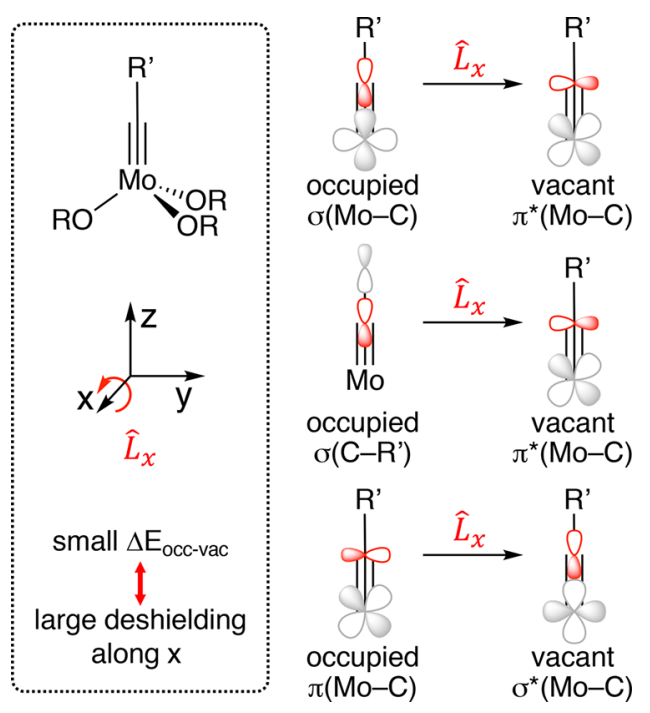

Figure 10. Three relevant orbital couplings.

investigation into metal alkylidynes showed that the $\sigma$ symmetric orbitals contribute to deshielding by a magnetic coupling with the low-lying vacant $\pi^{*}(\mathrm{M}-\mathrm{C})$ orbital, whereas the bonding $\pi(\mathrm{M}-\mathrm{C})$ orbital causes deshielding by interaction with the vacant $\sigma^{*}(\mathrm{M}-\mathrm{C})$ orbital. ${ }^{13}$ The computed geometries of $\mathbf{2 b}$ and $\mathbf{1 e}$ were found to reproduce the crystal structures well (for computational details, see the Supporting Information). The calculated isotropic shifts of $\mathbf{2} \mathbf{b}\left(\delta_{\mathrm{C}}=303 \mathrm{ppm}\right)$ and its podand cousin 1e $\left(\delta_{\mathrm{C}}=321 \mathrm{ppm}\right)$ show good agreement with the experimental values (307 and 312 ppm, respectively). Consistent with the experiment, the podand complex $\mathbf{l e}$ is more deshielded. Interestingly, all three principal components of the shielding tensor make small contributions that sum up to this net outcome (Figure 11). The larger deshielding of 1e suggests that the $\pi^{*}(\mathrm{Mo}-\mathrm{C})$ orbital as the LUMO of $1 \mathrm{e}$ is lower-lying than that of $\mathbf{2 b}$, which indicates a higher electrophilicity of the canopy variant. This conclusion is consistent with the strongly delocalized $\pi^{*}(\mathrm{Mo}-\mathrm{C})$ orbital (Figure 7): the lobes on the basal phenyl group of le suggest
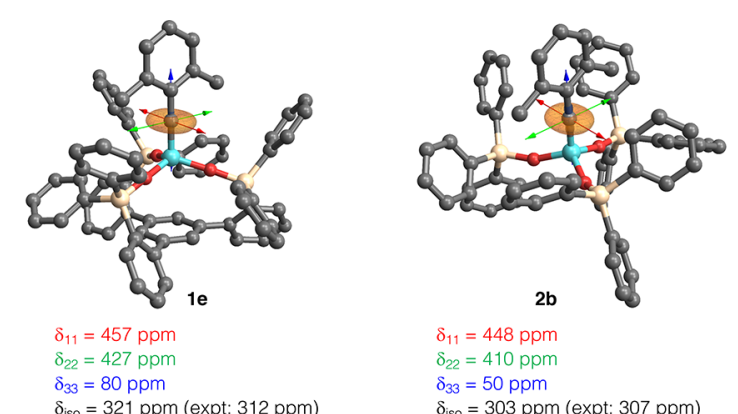

$\delta_{33}=80 \mathrm{ppm}$

$\delta_{\text {iso }}=321 \mathrm{ppm}(\operatorname{expt:} 312 \mathrm{ppm})$

$\delta_{11}=448 \mathrm{ppm}$

$\delta_{22}=410 \mathrm{ppm}$

$\delta_{33}=50 \mathrm{ppm}$

$\delta_{\text {iso }}=303$ ppm (expt: 307 ppm)

300 shielding

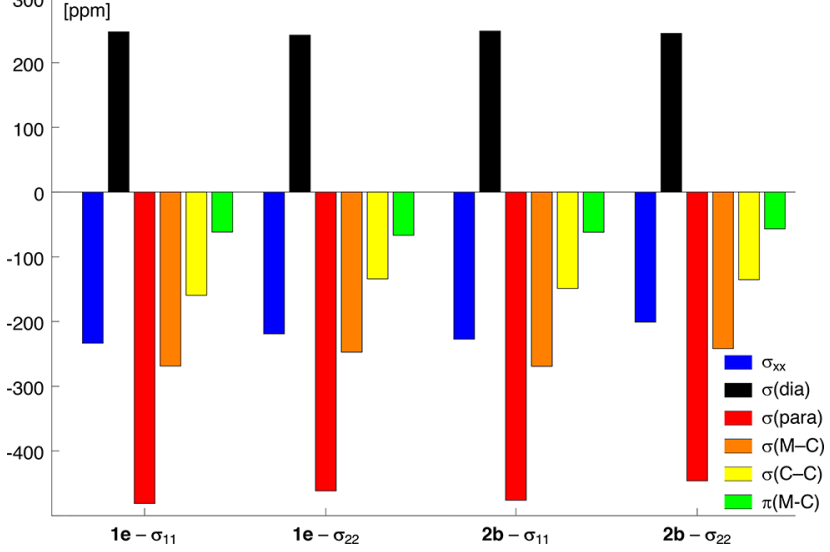

Figure 11. CST analysis of complexes $\mathbf{1 e}$ and $\mathbf{2 b}$.

that this remote substituent assists in lowering the energy of the LUMO.

Reactive Intermediates. It is not clear, a priori, whether the lower-lying LUMO of complexes of type $\mathbf{1}$ is an advantage for catalysis. As mentioned in the Introduction, it takes a wellbalanced electrophilicity management for a complex to become an efficient alkyne metathesis catalyst: a certain Lewis acidity is necessary for the $[2+2]$ cycloaddition to happen, ${ }^{7-10,53}$ but if the electrophilic character is too pronounced, the resulting metallacyclobutadiene is (over)stabilized and cycloreversion is disfavored (not to speak of the functional group tolerance that gets lost). ${ }^{13,14}$

It was therefore deemed relevant to check whether the more electrophilic canopy catalysts $\mathbf{1}$ might already enter the regime of (meta)stable metallacyclobutadienes. When $\mathbf{1 a}$ was treated with 3 -hexyne (5 equiv) in $\left[D_{8}\right]$-toluene in a temperature range between +23 and $+40{ }^{\circ} \mathrm{C}$, a new complex 18, which turned out to be a metallatetrahedrane, was detected rather than the expected metallacyclobutadiene 17 (Scheme 7). The Lee group had been the first to observe the formation of this unusual complex; because they managed to characterize 18 in detail by spectroscopic means and even X-ray crystallography, we refrained from repeating the entire exercise. ${ }^{2}$ Our observations fully confirm their lead finding; the fact that $\mathbf{1 8}$ is formed so easily implies that the metallatetrahedrane is slightly more stable than (or at least isoenergetic with) the starting molybdenum alkylidyne and the presumed metallacyclobutadiene $\mathbf{1 7}$ from which it is thought to derive according to theory. ${ }^{54}$ Because $1 \mathrm{a}$ is a competent catalyst (see below), the question arises about which role complex 18 plays in the catalytic process. On the basis of probability arguments, metallatetrahedranes had been considered as possible on-cycle intermediates, ${ }^{55}$ but computational studies and the isolation of a few unreactive representatives advocated 
Scheme 7. Discrete Intermediates Downstream from the Molybdenum Alkylidynes

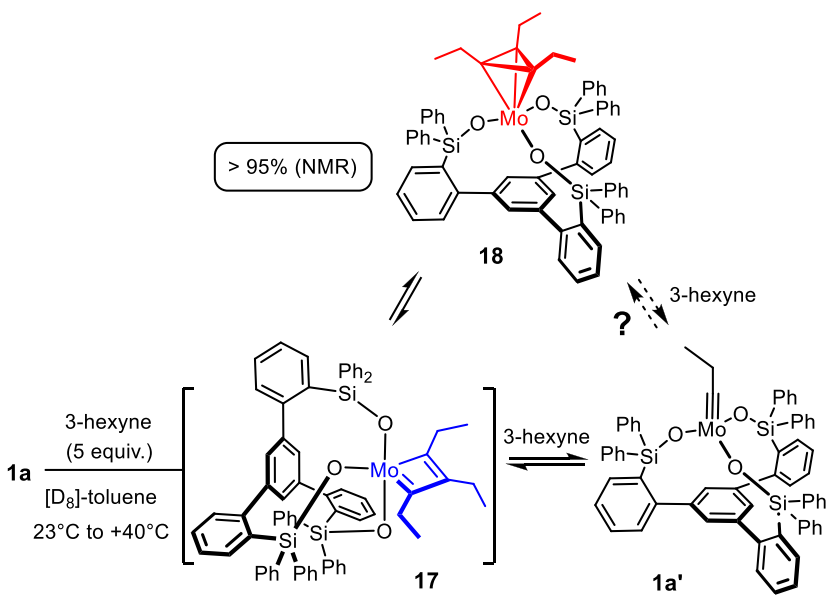

against this early assumption. ${ }^{56-59}$ Since then, it is generally believed that metallatetrahedranes are unreactive sinks and/or a gateway to decomposition. ${ }^{60}$

The recorded NMR data (EXSY, ROESY) show beyond a doubt that 18 exchanges with 3-hexyne as well as with the propylidyne complex $\mathbf{1} \mathbf{a}^{\prime}$, which proves that formation of the metallatetrahedrane is reversible (see the Supporting Information). However, the data gathered so far do not allow us to decide if $\mathbf{1 8}$ is a true on-cycle intermediate or just an off-cycle reservoir, which would be more in line with previous views. $^{56-58}$ If it is off the cycle, the high concentration of $\mathbf{1 8}$ in the mixture is a serious handicap because it keeps much of the active molybdenum species away from doing its job. This question is highly relevant for further optimization and hence subject to ongoing investigations in this laboratory.

Benchmarking of the Catalytic Activity. With a series of well-characterized tripodal alkylidyne complexes of type $\mathbf{1}$ in hand, we were in the position to study how steric and electronic changes impact on the catalytic properties. The homometathesis of 1-methoxy-4-(prop-1-yn-1-yl)benzene (19) to form 1,2-bis(4-methoxyphenyl)ethyne (20a) was chosen to benchmark the catalysts, each in monomeric form (Figure 12). To monitor their activity by NMR, the reaction was performed at $27{ }^{\circ} \mathrm{C}$ in the absence of molecular sieves as a 2-butyne-sequestering agent ${ }^{3}$ to avoid any interference. ${ }^{61}$ Therefore the reaction leads only to an equilibrium comprising ca. $45 \%$ of unreacted starting material.

1a as the prototype complex of the new series shows appreciable activity in that the equilibrium is reached in $\leq 100$ min. ${ }^{1}$ The reaction rate of $\mathbf{1 b}$ bearing fluorine substituents on the fence of the podand ligand is identical, within experimental error, whereas 1c containing $\mathrm{MeO}$ groups on the silanolate propellers is slightly less active. The comparison of $\mathbf{1 a}$ and $\mathbf{1 e}$, which differ from each other only in the substitution pattern of the benzylidyne, shows that the 2,6-dimethyl-substituted variant results in markedly slower conversion even though equilibrium is eventually reached. This result must also be seen in light of the report by the Lee group, who found that their complex bearing a 2,4,6-trimethylphenyl group induced scrambling of 1-methoxy-4-(phenylethynyl)benzene only upon heating. ${ }^{2}$ Taken together, these observations indicate that 2,6-disubstitution of the benzylidyne group causes slow(er) and/or incomplete initiation. Figure 12 also shows

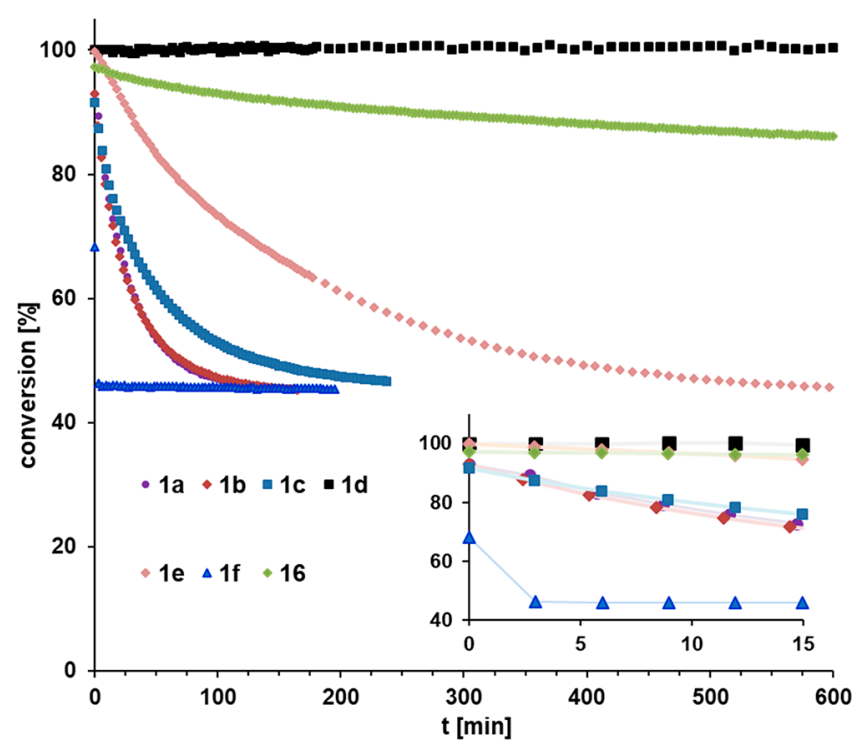

Figure 12. Benchmarking experiment $\left({ }^{1} \mathrm{H} \mathrm{NMR}\right)$ : consumption of 1methoxy-4-(prop-1-yn-1-yl)benzene (19) ([ $\left.\mathrm{D}_{8}\right]$-toluene, $0.1 \mathrm{M}, 27$ ${ }^{\circ} \mathrm{C}, 5 \mathrm{~mol} \%$ catalyst loading). The inset shows that the reaction catalyzed by $1 \mathrm{f}$ had reached equilibrium in $<5 \mathrm{~min}$, when the second data point was recorded.

that complex 16 with the carbinol ligand set exhibits much lower activity than 1a as the closest relative of the trisilanol series. This finding is in line with the notion that silanols are privileged ligands for molybdenum alkylidynes. ${ }^{3,4}$

Although 1a is a competent catalyst, it does not rival the parent complex 2 a carrying three simple monodentate $\mathrm{Ph}_{3} \mathrm{SiO}$ groups, which effects the model reaction in $\leq 10 \mathrm{~min}$. In our preliminary Communication, we conjectured that the higher rigidity of the tripodal scaffold might be the reason why the canopy variant $\mathbf{1 a}$ is $\sim 10$ times slower than $2 \mathbf{2 a}^{1}$ A stiffer backbone retards the changes back and forth between tetrahedral and trigonal-bipyramidal coordination geometries of the reactive intermediates passed through during a catalytic cycle. While this argument is certainly valid, the improved understanding of the nature of $\mathbf{1}$ makes us believe that additional factors might come into play. The accumulation of metallatetrahedrane $\mathbf{1 8}$ (see Scheme 7) is arguably relevant in this context: unless $\mathbf{1 8}$ itself is kinetically competitive, its formation in high concentration is a serious handicap as it siphons much of the active species into an off-cycle reservoir.

In any case, it seems that the ligand design must somehow counteract the build-up of Lewis acidity resulting from the distorted ligand sphere about the metal. Encouraged by the ${ }^{95}$ Mo NMR data, we tested the activity of $\mathbf{1 d}$ and $\mathbf{1 f}$ bearing more donating alkyl substituents on the Si bridges. The effect is massive, and the outcome is extreme. 1d endowed with isopropyl groups failed to catalyze the model reaction at ambient temperature (but does so in refluxing toluene), whereas its sibling $\mathbf{1 f}$ bearing methyl substituents is by far the most active precatalyst of the entire new series; it basically regains the activity of the parent complex $\mathbf{2 a}$ (Figure 12). We tentatively ascribe the striking difference between $\mathbf{1 d}$ and $\mathbf{1 f}$ to steric effects, supposing that the bulky isopropyl moieties disfavor or even prevent substrate binding (compare Figure 6). In any case, the performance of $\mathbf{1 f}$ is gratifying: this "turbo catalyst" is as reactive as its best ancestors but outperforms them by far in terms of functional group tolerance. 
Table 2. Homo-Metathesis and Ring-Closing Alkyne Metathesis Reactions in the Presence of Unprotected -OH Groups ${ }^{a}$

\begin{tabular}{|c|c|c|c|c|c|c|}
\hline Entry & Substrate & Product & & $2 a$ & $1 a$ & $1 f$ \\
\hline 1 & & & $20 \mathrm{~b}$ & $69 \%^{c}$ & $93 \%^{b}$ & \\
\hline 2 & & & 21a, $n=4$ & $0 \%$ & $69 \%$ & $73 \%$ \\
\hline 3 & & & 21b, $n=5$ & $0 \%$ & $66 \%$ & $71 \%$ \\
\hline 4 & & & 21c, $n=6$ & $0 \%$ & $83 \%$ & $88 \%$ \\
\hline 5 & & & 21d, $n=7$ & $0 \%$ & $91 \%$ & $87 \%$ \\
\hline 6 & & & 22 & $34 \%^{\mathrm{c}}$ & & $94 \%$ \\
\hline 7 & & & 23 & $0 \%$ & dimers $^{d}$ & $68 \%{ }^{\mathrm{e}}$ \\
\hline 8 & & & 24 & $16 \%^{f}$ & & $66 \%{ }^{5}$ \\
\hline 9 & & & 25 & $0 \%$ & $68 \%^{h}$ & \\
\hline
\end{tabular}

${ }^{a}$ Isolated yields of reactions performed with $5 \mathrm{~mol} \%$ of catalyst loading in toluene at RT in the presence of MS $5 \AA$, unless stated otherwise. ${ }^{b}$ At 60 ${ }^{\circ} \mathrm{C}$. ${ }^{c}$ With $10 \mathrm{~mol} \%$ of $\mathbf{2 a} .{ }^{d}$ Mostly formation of dimers (NMR). ${ }^{e}$ With $10 \mathrm{~mol} \%$ of catalyst at $110{ }^{\circ} \mathrm{C} .{ }^{f}$ Yield determined by high-performance liquid chromatography (HPLC); in addition, ca. $20 \%$ of what appeared to be dimeric products were detected. ${ }^{g}$ With 20 mol $\%$ of catalyst at $80{ }^{\circ} \mathrm{C}$. ${ }^{h}$ Using $30 \mathrm{~mol} \%$ of catalyst at reflux temperature; yield over two steps (metathetic ring closure and reductive cleavage of the 2,2,6,6tetramethylpiperidinyl group).

Scope and Applications. A truly comprehensive investigation into the functional group compatibility of the canopy complexes is beyond the scope of this Article, but the examples compiled below clearly show their promise.

The direct comparison of the parent triphenylsilanolate complex $2 \mathrm{a}$ with the new catalysts $1 \mathrm{a}$ and 1f is particularly instructive (Table 2): while 2a invariably failed to metathesize alkynes carrying unhindered primary alcohol groups, both canopy complexes afforded the desired products in good to excellent yields. As expected, catalyst 1 f reacted much faster than 1a (ca. 2 versus $16 \mathrm{~h}$ ), but their productivity is comparable, suggesting that different members of this family likely cover a similar substrate scope. The superior performance of the new catalysts is further illustrated by the formation of phenol $\mathbf{2 0 b}$ and product $\mathbf{2 2}$ carrying an ordinary secondary alcohol. The RCAM reaction leading to $\mathbf{2 3}$ containing two different propargylic substituents showcases two advantageous attributes at the same time: $\mathbf{2} \mathbf{a}$ is unable to cope with the unprotected $-\mathrm{OH}$ group, whereas both new catalysts are able to do so. However, only the slim turbo catalyst 1 f provides the targeted cyclic monomer, whereas 1a gave mostly dimeric products; this aspect becomes highly relevant in the context of the much more demanding cycloalkyne $\mathbf{5 1}$ as the key precursor for the marine macrolide amphidinolide $\mathrm{F}$ (see below).

Compatibility with a propargylic $-\mathrm{OH}$ group is quintessential for the formation of $\mathbf{2 4}$. It is also of note that two of the three alkyne groups in the substrate reacted selectively. ${ }^{22}$ Once again, the superiority of $\mathbf{1 f}$ is striking because the standard catalyst 2a gave a poor yield and a bad mass balance. Cycloalkyne 25 as the key intermediate of the first total synthesis of the marine nor-cembranoid sinulariadiolide further illustrates the excellent application profile, ${ }^{62}$ in that the new catalyst tolerates the free propargylic $-\mathrm{OH}$ but also an electron-rich enol ester as well as a hydroxylamine.

In line with our initial design concept, it is the chelate effect that largely accounts for the much improved compatibility with unprotected - $\mathrm{OH}$ groups; it even entails a certain metastability of the canopy catalysts toward water (Scheme 8). Whereas addition of either a primary alcohol or $\mathrm{H}_{2} \mathrm{O}(10$ equiv) to a solution of $\mathbf{2 b}$ in $\left[\mathrm{D}_{8}\right]$-toluene results in almost instantaneous solvolysis (hydrolysis) with quantitative release of $\mathrm{Ph}_{3} \mathrm{SiOH}$ ( $\leq 5 \mathrm{~min}, \mathrm{NMR}$ ), it takes $\sim 9 \mathrm{~h}$ until $1 \mathrm{e}$ is fully decomposed by water under otherwise identical conditions. Importantly, the spectra do not provide any indication for protonation of the alkylidyne: ligand exchange rather than

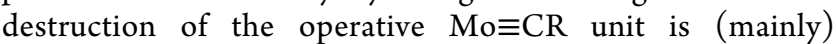
accountable for the loss of activity. This observation is in line with recent experimental as well as computational data from the literature. ${ }^{21,63}$ Although water remains ultimately detrimental, a half-life on the order of $1 \mathrm{~h}$ is a chemical virtue without precedent in metal alkylidyne chemistry in general; it is fully appreciated if one considers the extreme sensitivity of earlier generations of alkyne metathesis catalysts, not least the otherwise very powerful complex 3 and its precursors. ${ }^{7-10,34,64}$ In this context, we reiterate that it has become common practice to supplement the reaction mixtures with molecular sieves. ${ }^{3,4}$ Although this additive primarily serves as a sequestering agent for the released 2-butyne in reactions conducted at RT, it ensures a level of dryness and hence a lifespan of a canopy catalyst that allow certain applications to be carried out in technical-grade solvents that need not be rigorously dried and purified prior to use. Indeed, under these 


\section{Scheme 8. Positive Impact of the Chelate Effect}
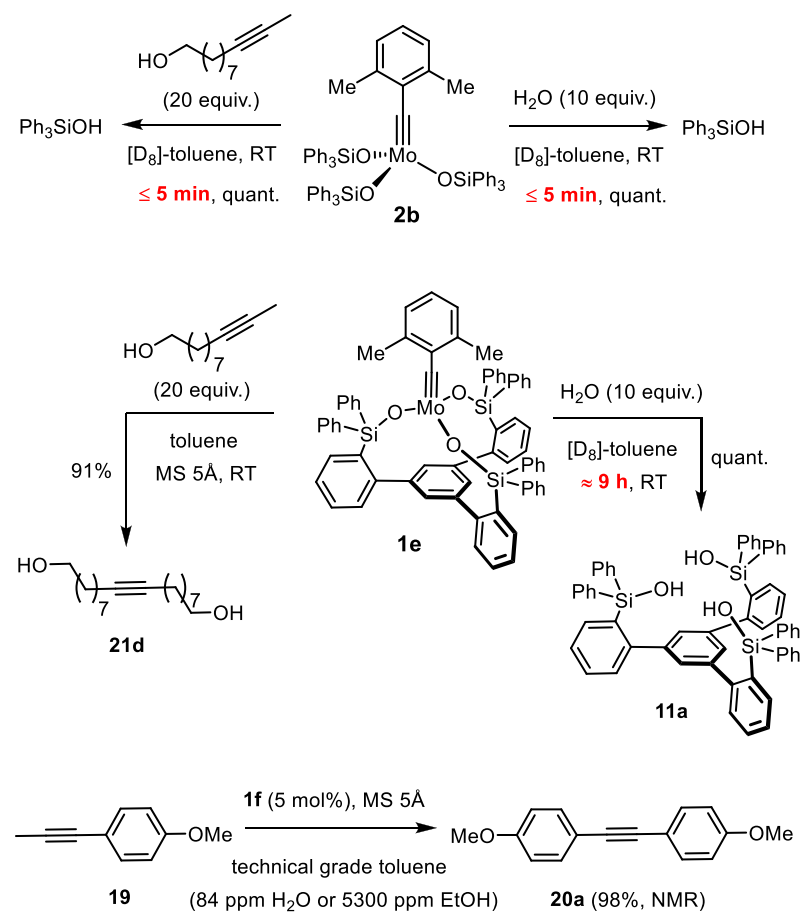

standard conditions, the test reaction used to benchmark the catalyst performance proceeded quantitatively in technicalgrade toluene ( $87 \mathrm{ppm}$ water) as well as in toluene containing residual $\mathrm{EtOH}(5300 \mathrm{ppm})$ in the presence of MS $5 \AA$. Although there is certainly very much room for improvement, these preliminary data are encouraging and show that the podand ligand structure pays a valuable dividend in practical terms too.

In view of the foregoing, it will not come as a surprise that various other protic sites are also well-tolerated by the new catalysts, including a free phenol, amides, carbamates, malonates, $\beta$-ketoesters, sulfones, and the fluorenyl group (Table 2 and Schemes 9, 10, 11, and 12). $\beta$-Ketoesters in

\section{Scheme 9. Homo-Metathesis Reactions of Substrates} Comprising $\mathrm{C}-\mathrm{H}$ and/or $\mathrm{N}-\mathrm{H}$ Acidic Sites ${ }^{a}$<smiles>COC(=O)C(CC#CCC(C(C)=O)C(C)=O)C(=O)OC</smiles>

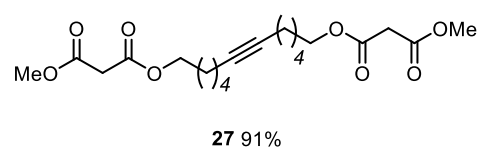<smiles>COC(=O)C(CC#CCC(NC(C)=O)C(=O)OCc1ccccc1)NC(C)=O</smiles>

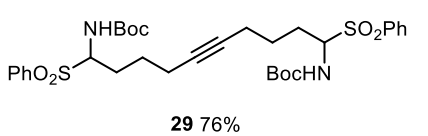

${ }^{a_{T}}$ The reactions were performed with $\mathbf{1 a}(5 \mathrm{~mol} \%)$ in toluene at RT in the presence of MS $5 \AA .{ }^{b}$ At $90{ }^{\circ} \mathrm{C}$ with $10 \mathrm{~mol} \%$ of catalyst.

particular caused problems in the past for the parent complexes 2,5 whereas the new catalyst 1 a furnished product 26 containing this common motif in good yield.

Because our spectral and computational data had suggested that the podand ligand architecture upregulates the Lewis acidity, it was deemed equally important to prove that the new catalysts remain active in the presence of various donor sites.
Scheme 10. Survey of the Functional Group Tolerance: Homo-Metathesis Reactions

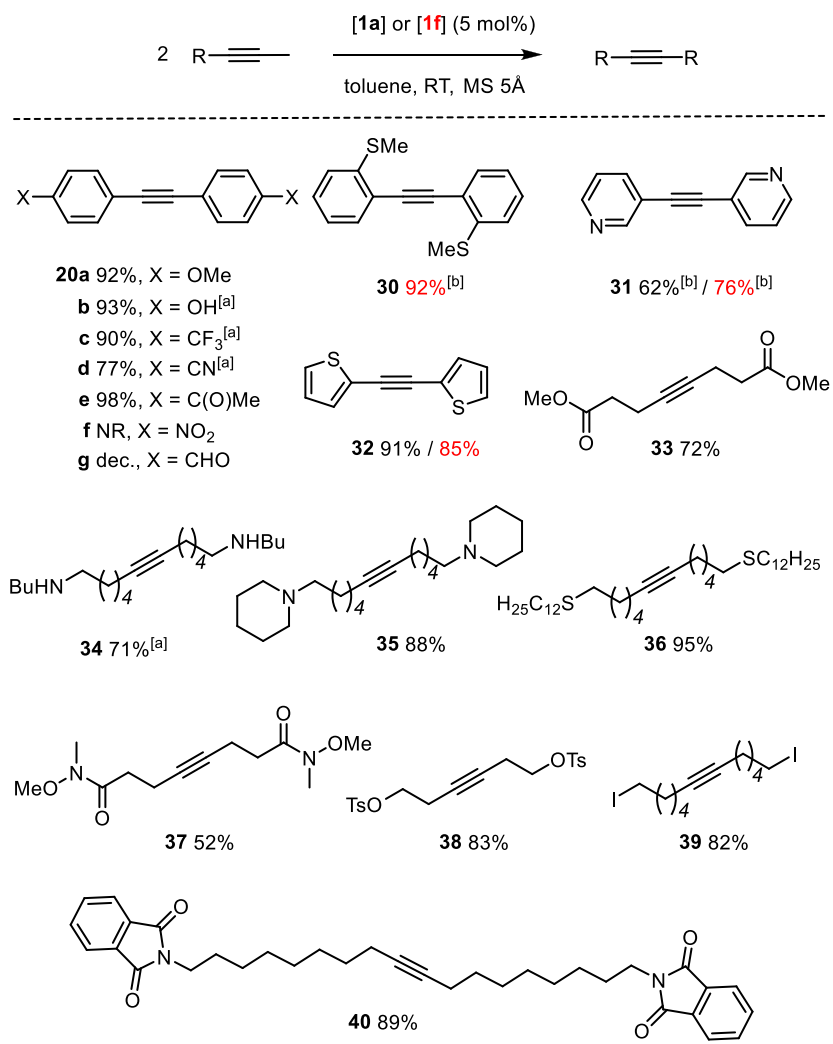

${ }^{a}$ The choice of catalyst is color-coded; at $60{ }^{\circ} \mathrm{C} .{ }^{b} \mathrm{At} 90{ }^{\circ} \mathrm{C}$; $\mathrm{NR}=$ no reaction

Scheme 11. Ring-Closing Alkyne Metathesis (RCAM): Test Reactions $^{a}$

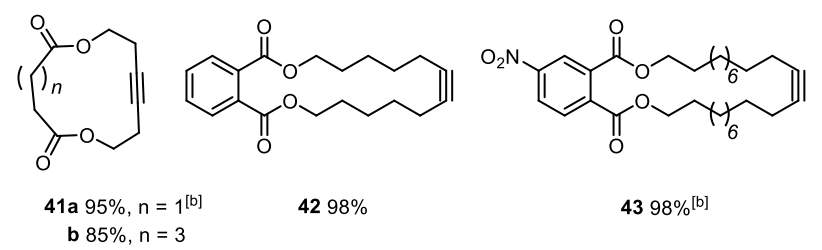

${ }^{a}$ Unless stated otherwise, all reactions were performed with 1 a (5 mol $\%)$ in toluene in the presence of powdered MS $5 \AA$ at ambient temperature. ${ }^{b}$ At $60{ }^{\circ} \mathrm{C}$.

Although gentle heating was necessary in several cases, it is rewarding to find that basic nitrogen in the form of a pyridine (31), a secondary or tertiary amine (34 and 35), or a hydroxylamine (25) does not bring metathesis to a halt. The same is true for a nitrile-containing compound (20d), even though the structure of the adduct $[\mathbf{1 a} \cdot \mathrm{MeCN}]$ had shown that cyano groups exhibit appreciable affinity to the molybdenum center. The good results with thioethers and various sulfurcontaining heterocycles $(30,32,36$, and 47$)$ are equally remarkable, as is the compatibility with a Weinreb amide (37), which is a potential chelate ligand for a high-valent transition metal center.

Auspicious results were also obtained with yet other exigent functionality. An elimination-prone primary tosylate and a primary iodide went uncompromised (38 and 39). The ringclosing alkyne metathesis (RCAM) reaction leading to 
Scheme 12. Formation of Key Intermediates of Previous Natural Product Total Syntheses ${ }^{a}$
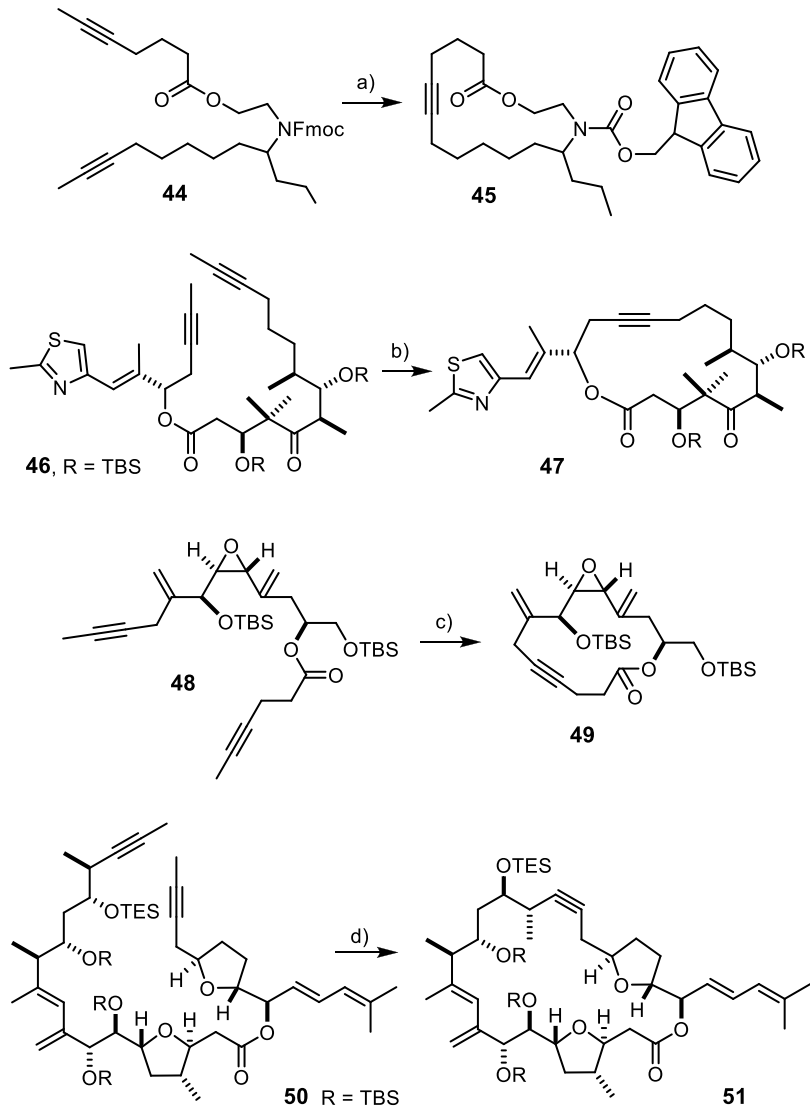

${ }^{a}$ Reagents and conditions: (a) 1a (5 mol \%), toluene, MS $5 \AA$, RT, quant.; (b) 1a (5 mol \%), toluene, MS $5 \AA$, $60{ }^{\circ} \mathrm{C}$, $75 \%$; (c) 1 a ( $5 \mathrm{~mol}$ $\%)$, toluene, MS $5 \AA$, RT, $85 \%$; (d) 1 f ( $30 \mathrm{~mol} \%)$, toluene, MS $5 \AA$, $80{ }^{\circ} \mathrm{C}, 81 \%$.

cycloalkyne $\mathbf{4 3}$ proves that a nitro group, as such, is compatible (Scheme 11); however, attempted formation of the nitrosubstituted tolane derivative $\mathbf{2 0 f}$ failed even at elevated temperature. This limitation shows that electron-deficient alkynes in general are quite refractory substrates. ${ }^{65}$ The observation that other products bearing electron-withdrawing substituents required more forcing conditions corroborates this aspect (20c,d and 31). Attempted formation of the aldehyde derivative $20 \mathrm{~g}$, however, resulted in decomposition. Aldehydes have previously been found incompatible, a limitation that obviously persists; ${ }^{3-5}$ ketones, in contrast, pose no problem (20e, 26, and 47).

The rewarding outcome of the model reactions made us confident that the new catalysts qualify for more advanced applications. Material from previous total synthesis campaigns from our laboratory provided us with the opportunity to confirm this expectation. The two demanding cases $\mathbf{2 4}$ and $\mathbf{2 5}$ (Table 2) have already been discussed earlier in the context of the tolerance of the new catalysts toward unprotected $-\mathrm{OH}$ groups. Next, we reprepared product 45 , which is a key precursor for the synthesis of homoepilachnene, an ingredient of the defense secretions of the pupae of a Mexican beetle (Scheme 12); ${ }^{66}$ although rather simple in structural terms, this example shows the compatibility of 1 a with a base-sensitive $\mathrm{C}-\mathrm{H}$ acidic fluorenyl group. Clearly more challenging is the formation of cycloalkyne 47, which leads to the potent anticancer agent epothilone $\mathrm{C}$ upon Lindlar reduction of the triple bond; ${ }^{67}$ the thiazole ring of $\mathbf{4 7}$ adds an important entry to the list of heterocycles that do not quench the catalyst's activity. Equally noteworthy is the fact that the eliminationprone aldol substructure and the ketone are not affected. Even more compelling evidence for the mildness of the method is found in the successful formation of 49, an immediate precursor of amphidinolide $\mathrm{V}:{ }^{68}$ the vinyl epoxide and the allyl ether subunits are both sensitive to acid and/or base yet remain intact. As expected, the double bonds present in the substrate are tolerated, in line with observations already made with previous generations of alkyne metathesis catalysts. ${ }^{3-10}$

The successful formation of $\mathbf{5 1}$ as the key intermediate en route to the marine toxin amphidinolide $\mathrm{F}^{69}$ illustrates yet another relevant aspect: only the slim turbo catalyst $1 \mathrm{f}$ allowed this densely decorated macrocycle to be formed in good yield, whereas 1a afforded acyclic dimers by homo-metathesis; complex 2a with $\mathrm{Ph}_{3} \mathrm{SiO}$ - ligands had also largely caused homodimerization, most likely as a result of steric hindrance about one of the double bonds in diyne 50. ${ }^{69}$ The leaner ligand sphere of $\mathbf{1 f}$ obviously helps to overcome yet another of the few limitations that siloxide-based alkyne metathesis catalysts had faced in the past (see also entry 7 in Table 2). ${ }^{19}$

Overall, the functional group tolerance of catalysts of type 1 is deemed remarkable and certainly unrivaled by any other molecularly defined alkyne metathesis catalyst known to date. From the conceptual viewpoint, this excellent profile may help to correct the common misperception that high-valent early transition metal catalysts in general and $\mathrm{Mo}^{\mathrm{VI}}$-based alkylidyne and alkylidene catalysts in particular provide only limited opportunities when working with polyfunctionalized compounds. $^{70}$

\section{CONCLUSIONS}

The new family of well-defined molybdenum alkylidyne complexes endowed with a distinctive podand topology is distinguished by good to excellent catalytic activity for alkyne metathesis and a truly remarkable compatibility with exigent functionality, including various free $-\mathrm{OH}$ groups and several other protic sites. It is largely due to the chelate effect that even a certain stability toward water was noticed, which is without parallel in the literature. Because the preparation of the required ligands is straightforward on a multigram scale, their design is inherently modular, and the complexes themselves are readily prepared; they might very well mark an important milestone in the development of ever more efficient alkyne metathesis catalysts. Ongoing studies in our laboratory intend to gain additional insights into the factors relevant for catalysis, study the pertinent reactive intermediates, improve activity and stability even further, map the functional group tolerance in greater detail, extend the coverage beyond molybdenum, and showcase the virtues of the new catalysts by advanced applications.

\section{ASSOCIATED CONTENT}

\section{Supporting Information}

The Supporting Information is available free of charge at https://pubs.acs.org/doi/10.1021/jacs.0c04742.

Experimental section including supporting X-ray structures, crystallographic abstracts, characterization data, and computational details (PDF)

Copies of NMR spectra of new compounds (PDF) 
Crystallographic data (ZIP)

\section{AUTHOR INFORMATION}

\section{Corresponding Author}

Alois Fürstner - Max-Planck-Institut für Kohlenforschung, 45470 Mülheim/Ruhr, Germany; 이이.org/0000-00030098-3417; Email: fuerstner@kofo.mpg.de

\section{Authors \\ Julius Hillenbrand - Max-Planck-Institut für Kohlenforschung, 45470 Mülheim/Ruhr, Germany \\ Markus Leutzsch - Max-Planck-Institut für Kohlenforschung, 45470 Mülheim/Ruhr, Germany; 이이.org/0000-0001- 8171-9399 \\ Ektoras Yiannakas - Max-Planck-Institut für Kohlenforschung, 45470 Mülheim/Ruhr, Germany \\ Christopher P. Gordon - Department of Chemistry and Applied Biosciences, ETH Zürich, 8093 Zürich, Switzerland; (1) orcid.org/0000-0002-2199-8995 \\ Christian Wille - Max-Planck-Institut für Kohlenforschung, 45470 Mülheim/Ruhr, Germany \\ Nils Nöthling - Max-Planck-Institut für Kohlenforschung, 45470 Mülheim/Ruhr, Germany \\ Christophe Copéret - Department of Chemistry and Applied Biosciences, ETH Zürich, 8093 Zürich, Switzerland; \\ (1) orcid.org/0000-0001-9660-3890}

Complete contact information is available at:

https://pubs.acs.org/10.1021/jacs.0c04742

\section{Notes}

The authors declare no competing financial interest.

\section{ACKNOWLEDGMENTS}

Generous financial support by the MPG, the Leverhulme Trust (studentship to E.Y.), and Scholarship Fund of the Swiss Chemical Industry (SSCI fellowship to C.P.G.) is gratefully acknowledged. We thank all analytical departments of our Institute for valuable support, especially Mr. J. Rust and Prof. C. W. Lehmann for the excellent X-ray service, Dr. R. Goddard for valuable discussions, and Dr. C. Farès and M.Sc. J. B. Lingnau for assistance with various NMR analyses.

\section{REFERENCES}

(1) Hillenbrand, J.; Leutzsch, M.; Fürstner, A. Molybdenum Alkylidyne Complexes with Tripodal Silanolate Ligands: The Next Generation of Alkyne Metathesis Catalysts. Angew. Chem., Int. Ed. 2019, 58, 15690-15696.

(2) Thompson, R. R.; Rotella, M. E.; Du, P.; Zhou, X.; Fronczek, F. R.; Kumar, R.; Gutierrez, O.; Lee, S. Siloxide Podand Ligand Scaffold for Molybdenum-Catalyzed Alkyne Metathesis and Isolation of a Dynamic Metallatetrahedrane Intermediate. Organometallics 2019, 38, 4054-4059.

(3) (a) Heppekausen, J.; Stade, R.; Goddard, R.; Fürstner, A. Practical New Silyloxy-based Alkyne Metathesis Catalysts with Optimized Activity and Selectivity Profiles. J. Am. Chem. Soc. 2010, 132, 11045-11057. For the lead finding that siloxides are outstanding ligands for Mo-based catalysts, see: (b) Bindl, M.; Stade, R.; Heilmann, E. K.; Picot, A.; Goddard, R.; Fürstner, A. Molybdenum Nitride Complexes with $\mathrm{Ph}_{3} \mathrm{SiO}$ - Ligands are Exceedingly Practical and Tolerant Precatalysts for Alkyne Metathesis and Efficient Nitrogen Transfer Agents. J. Am. Chem. Soc. 2009, 131, 9468-9470.

(4) Heppekausen, J.; Stade, R.; Kondoh, A.; Seidel, G.; Goddard, R.; Fürstner, A. Optimized Synthesis, Structural Investigations, Ligand
Tuning and Synthetic Evaluation of Silyloxy-based Alkyne Metathesis Catalysts. Chem. - Eur. J. 2012, 18, 10281-10299.

(5) (a) Persich, P.; Llaveria, J.; Lhermet, R.; de Haro, T.; Stade, R.; Kondoh, A.; Fürstner, A. Increasing the Structural Span of Alkyne Metathesis. Chem. - Eur. J. 2013, 19, 13047-13058. (b) Lhermet, R.; Fürstner, A. Cross-Metathesis of Terminal Alkynes. Chem. - Eur. J. 2014, 20, 13188-13193.

(6) Lackner, A.; Fürstner, A. The Triple-Bond Metathesis of Aryldiazonium Salts: A Prospect for Dinitrogen Cleavage. Angew. Chem., Int. Ed. 2015, 54, 12814-12818.

(7) Fürstner, A. Alkyne Metathesis on the Rise. Angew. Chem., Int. Ed. 2013, 52, 2794-2819.

(8) Fürstner, A. Teaching Metathesis "Simple" Stereochemistry. Science 2013, 341, 1229713.

(9) Ehrhorn, H.; Tamm, M. Well-Defined Alkyne Metathesis Catalysts: Developments and Recent Applications. Chem. - Eur. J. 2018, 25, 3190-3208.

(10) (a) Schrock, R. R.; Czekelius, C. Recent Advances in the Synthesis and Applications of Molybdenum and Tungsten Alkylidene and Alkylidyne Catalysts for the Metathesis of Alkenes and Alkynes. Adv. Synth. Catal. 2007, 349, 55-77. (b) Zhang, W.; Moore, J. S. Alkyne Metathesis: Catalysts and Synthetic Applications. Adv. Synth. Catal. 2007, 349, 93-120. (c) Fürstner, A.; Davies, P. W. Alkyne Metathesis. Chem. Commun. 2005, 2307-2320. (d) Mortreux, A.; Coutelier, O. Alkyne Metathesis Catalysts: Scope and Future. J. Mol. Catal. A: Chem. 2006, 254, 96-104. (e) Yang, H.; Jin, Y.; Du, Y.; Zhang, W. Application of Alkyne Metathesis in Polymer Synthesis. J. Mater. Chem. A 2014, 2, 5986-5993.

(11) (a) Schrock, R. R. Multiple Metal-Carbon Bonds for Catalytic Metathesis Reactions. Angew. Chem., Int. Ed. 2006, 45, 3748-3759. (b) Schrock, R. R. High Oxidation State Multiple Metal-Carbon Bonds. Chem. Rev. 2002, 102, 145-180.

(12) Krempner, C. Role of Siloxides in Transition Metal Chemistry and Homogeneous Catalysis. Eur. J. Inorg. Chem. 2011, 2011, 16891698.

(13) An instructive illustration is manifest in a volcano-type correlation: increasing electrophilicity of the alkylidyne leads to higher activity up to a certain point, at which the metallacyclobutadiene intermediate becomes (too) stable and the retrocycloaddition (too) slow; see: Estes, D. P.; Gordon, C. P.; Fedorov, A.; Liao, W.-C.; Ehrhorn, H.; Bittner, C.; Zier, M. L.; Bockfeld, D.; Chan, K. W.; Eisenstein, O.; Raynaud, C.; Tamm, M.; Copéret, C. Molecular and Silica-Supported Molybdenum Alkyne Metathesis Catalysts: Influence of Electrons and Dynamics on Activity Revealed by Kinetics, Solid-State NMR, and Chemical Shift Analysis. J. Am. Chem. Soc. 2017, 139, 17597-17607.

(14) Yet another illustration that electrophilicity management is critical for success can be seen in the fact that unfluorinated and perfluorinated tert-butoxy ligands entail no or very low activity, whereas trifluoro- and hexafluoro-tert-butoxy groups give competent molybdenum alkylidyne catalysts; see: (a) McCullough, L. G.; Schrock, R. R. Metathesis of Acetylenes by Molybdenum(VI) Alkylidyne Complexes. J. Am. Chem. Soc. 1984, 106, 4067-4068. (b) McCullough, L. G.; Schrock, R. R.; Dewan, J. C.; Murdzek, J. C. Preparation of Trialkoxymolybdenum(VI) Alkylidyne Complexes, Their Reactions with Acetylenes, and the X-ray Structure of $\mathrm{Mo}\left[\mathrm{C}_{3}\left(\mathrm{CMe}_{3}\right)_{2}\right]\left[\mathrm{OCH}\left(\mathrm{CF}_{3}\right)_{2}\right]_{2}\left(\mathrm{C}_{5} \mathrm{H}_{5} \mathrm{~N}\right)_{2}$. J. Am. Chem. Soc. 1985, 107, 5987-5998. (c) Bittner, C.; Ehrhorn, H.; Bockfeld, D.; Brandhorst, K.; Tamm, M. Tuning the Catalytic Alkyne Metathesis Activity of Molybdenum and Tungsten 2,4,6-Trimethylbenzylidyne Complexes with Fluoroalkoxide Ligands $\mathrm{OC}\left(\mathrm{CF}_{3}\right)_{\mathrm{n}} \mathrm{Me}_{3-\mathrm{n}}$. Organometallics 2017, 36, 3398-3406.

(15) Certain alkylsilanolates also lead to active catalysts but have been studied less systematically; see refs 4 and 22 .

(16) See, for example: (a) Willwacher, J.; Kausch-Busies, N.; Fürstner, A. Divergent Total Synthesis of the Antimitotic Agent Leiodermatolide. Angew. Chem., Int. Ed. 2012, 51, 12041-12046. (b) Kwon, Y.; Schulthoff, S.; Dao, Q. M.; Wirtz, C.; Fürstner, A. Total 
Synthesis of Disciformycin A and B: Unusually Exigent Targets of Biological Significance. Chem. - Eur. J. 2018, 24, 109-114.

(17) (a) Micoine, K.; Fürstner, A. Concise Total Synthesis of the Potent Translation and Cell Migration Inhibitor Lactimidomycin. J. Am. Chem. Soc. 2010, 132, 14064-14066. (b) Hickmann, V.; Kondoh, A.; Gabor, B.; Alcarazo, M.; Fürstner, A. Catalysis-based and Protecting-Group-free Total Syntheses of the Marine Oxylipins Hybridalactone and the Ecklonialactones A, B, and C. J. Am. Chem. Soc. 2011, 133, 13471-13480. (c) Benson, S.; Collin, M.-P.; Arlt, A.; Gabor, B.; Goddard, R.; Fürstner, A. Second-Generation Total Synthesis of Spirastrellolide F Methyl Ester: The Alkyne Route. Angew. Chem., Int. Ed. 2011, 50, 8739-8744. (d) Chaladaj, W.; Corbet, M.; Fürstner, A. Total Synthesis of Neurymenolide A Based on a Gold-Catalyzed Synthesis of 4-Hydroxy-2-pyrones. Angew. Chem., Int. Ed. 2012, 51, 6929-6933. (e) Willwacher, J.; Fürstner, A. Catalysis-Based Total Synthesis of Putative Mandelalide A. Angew. Chem., Int. Ed. 2014, 53, 4217-4221. (f) Hoffmeister, L.; Persich, P.; Fürstner, A. Formal Total Synthesis of Kendomycin by Way of Alkyne Metathesis/Gold Catalysis. Chem. - Eur. J. 2014, 20, 4396-4402. (g) Lehr, K.; Schulthoff, S.; Ueda, Y.; Mariz, R.; Leseurre, L.; Gabor, B.; Fürstner, A. A New Method for the Preparation of Non-Terminal Alkynes: Application to the Total Synthesis of Tulearin A and C. Chem. - Eur. J. 2015, 21, 219-227. (h) Hoffmeister, L.; Fukuda, T.; Pototschnig, G.; Fürstner, A. Total Synthesis of an Exceptional Brominated 4-Pyrone Derivative of Algal Origin: An Exercise in Gold Catalysis and Alkyne Metathesis. Chem. - Eur. J. 2015, 21, 45294533. (i) Ungeheuer, F.; Fürstner, A. Concise Total Synthesis of Ivorenolide B. Chem. - Eur. J. 2015, 21, 11387-11392. (j) Rummelt, S. M.; Preindl, J.; Sommer, H.; Fürstner, A. Selective Formation of a Trisubstituted Alkene Motif by trans-Hydrostannation/Stille Coupling: Application to the Total Synthesis and Late-Stage Modification of 5,6-Dihydrocineromycin B. Angew. Chem., Int. Ed. 2015, 54, 62416245. (k) Fuchs, M.; Fürstner, A. trans-Hydrogenation: Application to a Concise and Scalable Synthesis of Brefeldin A. Angew. Chem., Int. Ed. 2015, 54, 3978-3982. (1) Ahlers, A.; de Haro, T.; Gabor, B.; Fürstner, A. Concise Total Synthesis of Enigmazole A. Angew. Chem., Int. Ed. 2016, 55, 1406-1411. (m) Meng, Z.; Souillart, L.; Monks, B.; Huwyler, N.; Herrmann, J.; Müller, R.; Fürstner, A. A, ,MotifOriented" Total Synthesis of Nannocystin Ax. Preparation and Biological Evaluation of Analogues. J. Org. Chem. 2018, 83, 69776994.

(18) (a) Neuhaus, C. M.; Liniger, M.; Stieger, M.; Altmann, K.-H. Total Synthesis of the Tubulin Inhibitor WF-1360F Based on Macrocycle Formation through Ring-Closing Alkyne Metathesis. Angew. Chem., Int. Ed. 2013, 52, 5866-5870. (b) Ralston, K. J.; Ramstadius, H. C.; Brewster, R. C.; Niblock, H. S.; Hulme, A. N. SelfAssembly of Disorazole C1 Through a One-Pot Alkyne Metathesis Homodimerization Strategy. Angew. Chem., Int. Ed. 2015, 54, 70867090. (c) Burnley, J.; Jackson, W. R.; Robinson, A. J. One-Pot Selective Homodimerization/Hydrogenation Strategy for Sequential Dicarba Bridge Formation. J. Org. Chem. 2015, 80, 9057-9063. (d) Guo, L.-D.; Huang, X.-Z.; Luo, S.-P.; Cao, W.-S.; Ruan, Y.-P.; Ye, J.-L.; Huang, P.-Q. Organocatalytic, Asymmetric Total Synthesis of (-)-Haliclonin A. Angew. Chem., Int. Ed. 2016, 55, 4064-4068. (e) Boeckman, R. K., Jr.; Wang, H.; Rugg, K. W.; Genung, N. E.; Chen, K.; Ryder, T. R. A Scalable Total Synthesis of (-)-Nakadomarin A. Org. Lett. 2016, 18, 6136-6139. (f) Herstad, G.; Molesworth, P. P.; Miller, C.; Benneche, T.; Tius, M. A. RingClosing Metathesis in an Enantioselective Synthesis of the Macrocyclic Core of Crassin Acetate. Tetrahedron 2016, 72, 2084-2093. (g) Vendeville, J.-B.; Matters, R. E.; Chen, A.; Light, M. E.; Tizzard, G. J.; Chai, C. L. L.; Harrowven, D. C. A Synthetic Approach to Chrysophaerntin F. Chem. Commun. 2019, 55, 4837-4840. For applications in which the catalysts were generated in situ from nitride precursors as described in ref $3 \mathrm{~b}$, see: (h) Fouché, M.; Rooney, L.; Barrett, A. G. M. Biomimetic Total Synthesis of Cruentaren A via Aromatizaiton of Diketodioxinones. J. Org. Chem. 2012, 77, 30603070. (i) Smith, B. J.; Sulikowski, G. A. Total Synthesis of (士)-Haliclonacylamine C. Angew. Chem., Int. Ed. 2010, 49, 1599-
1602. (j) Nilson, M. G.; Funk, R. L. Total Synthesis of (-)-Nakadomarin A. Org. Lett. 2010, 12, 4912-4915.

(19) For pertinent examples, see: (a) Gebauer, K.; Fürstner, A. Total Synthesis of the Biphenyl Alkaloid (-)-Lythranidine. Angew. Chem., Int. Ed. 2014, 53, 6393-6396. (b) Mailhol, D.; Willwacher, J.; Kausch-Busies, N.; Rubitski, E. E.; Sobol, Z.; Schuler, M.; Lam, M.H.; Musto, S.; Loganzo, F.; Maderna, A.; Fürstner, A. Synthesis, Molecular Editing, and Biological Assessment of the Potent Cytotoxin Leiodermatolide. J. Am. Chem. Soc. 2014, 136, 15719-15729. (c) Karier, P.; Ungeheuer, F.; Ahlers, A.; Anderl, F.; Wille, C.; Fürstner, A. Metathesis at an Implausible Site: A Formal Total Synthesis of Rhizoxin D. Angew. Chem., Int. Ed. 2019, 58, 248-253.

(20) (a) Cromm, P. M.; Schaubach, S.; Spiegel, J.; Fürstner, A.; Grossmann, T. N.; Waldmann, H. Orthogonal Ring-Closing Alkyne and Olefin Metathesis for the Synthesis of Small GTPase-targeting Bicyclic Peptides. Nat. Commun. 2016, 7, 11300. (b) Cromm, P. M.; Wallraven, K.; Glas, A.; Bier, D.; Fürstner, A.; Ottmann, C.; Grossmann, T. N. Contraining an Irregular Peptide Secondary Structure through Ring-Closing Alkyne Metathesis. ChemBioChem 2016, 17, 1915-1919.

(21) For illustrations how protonation of the alkylidyne can be used to advantage, see: (a) Bukhryakov, K. V.; Schrock, R. R.; Hoveyda, A. H.; Tsay, C.; Müller, P. Syntheses of Molybdenum Oxo Alkylidene Complexes through Addition of Water to an Alkylidyne Complex. J. Am. Chem. Soc. 2018, 140, 2797-2800. (b) Zhai, F.; Bukhryakov, K. V.; Schrock, R. R.; Hoveyda, A. H.; Tsay, C.; Müller, P. Syntheses of Molybdenum Oxo Benzylidene Complexes. J. Am. Chem. Soc. 2018, 140, 13609-13613.

(22) Schaubach, S.; Gebauer, K.; Ungeheuer, F.; Hoffmeister, L.; Ilg, M. K.; Wirtz, C.; Fürstner, A. A Two-Component Alkyne Metathesis Catalyst System with an Improved Substrate Scope and Functional Group Tolerance: Development and Applications to Natural Product Synthesis. Chem. - Eur. J. 2016, 22, 8494-8507.

(23) (a) Jyothish, K.; Zhang, W. Introducing a Podand Motif to Alkyne Metathesis Catalyst Design: A Highly Active Multidentate Molybdenum(VI) Catalyst that Resists Alkyne Polymerization. Angew. Chem., Int. Ed. 2011, 50, 3435-3438. (b) Jyothish, K.; Wang, Q.; Zhang, W. Highly Active Multidentate Alkyne Metathesis Catalysts: Ligand-Activity Relationship and Their Applications in Efficient Synthesis of Porphyrin-Based Aryleneethynylene Polymers. Adv. Synth. Catal. 2012, 354, 2073-2078. (c) Yang, H.; Liu, Z.; Zhang, W. Multidentate Triphenolsilane-Based Alkyne Metathesis Catalysts. Adv. Synth. Catal. 2013, 355, 885-890. (d) Du, Y.; Yang, H.; Zhu, C.; Ortiz, M.; Okochi, K. D.; Shoemaker, R.; Jin, Y.; Zhang, W. Highly Active Multidentate Ligand-Based Alkyne Metathesis Catalysts. Chem. - Eur. J. 2016, 22, 7959-7963. (e) Paley, D. W.; Sedbrook, D. F.; Decatur, J.; Fischer, F. R.; Steigerwald, M. L.; Nuckolls, C. AlcoholPromoted Ring-Opening Alkyne Metathesis Polymerization. Angew. Chem., Int. Ed. 2013, 52, 4591-4594.

(24) For other alkylidyne complexes containing pincer-type ligands, see: (a) O’Reilly, M. E.; Ghiviriga, I.; Abboud, K. A.; Veige, A. S. A New $\mathrm{ONO}^{3-}$ Trianionic Pincer-Type Ligand for Generating Highly Nucleophilic Metal-Carbon Multiple Bonds. J. Am. Chem. Soc. 2012, 134, 11185-11195. (b) O’Reilly, M. E.; Nadif, S. S.; Ghiviriga, I.; Abboud, K. A.; Veige, A. S. Synthesis and Characterization of Tungsten Alkylidene and Alkylidyne Complexes Supported by a New Pyrrolide-Centered Trianionic $\mathrm{ONO}^{3-}$ Pincer Type Ligand. Organometallics 2014, 33, 836-839. (c) Roland, C. D.; VenkatRamani, S.; Jakhar, V. K.; Ghiviriga, J.; Abboud, K. A.; Veige, A. S. Synthesis and Characterization of a Molybdenum Alkylidyne Supported by a Trianionic $\mathrm{OCO}^{3-}$ Pincer Ligand. Organometallics 2018, 37, 45004505. (d) Bellone, D. E.; Bours, J.; Menke, E. H.; Fischer, F. R. Highly Selective Molybdenum ONO Pincer Complex Initiates the Living Ring-Opening Metathesis Polymerization of Strained Alkynes with Exceptionally Low Polydispersity Indices. J. Am. Chem. Soc. 2015, 137, 850-856. (e) Elser, I.; Groos, J.; Hauser, P. M.; Koy, M.; van der Ende, M.; Wang, D.; Frey, W.; Wurst, K.; Meisner, J.; Ziegler, F.; Kästner, J.; Buchmeiser, M. R. Molybdenum and Tungsten Alkylidyne 
Complexes Containing Mono-, Bi-, and Tridentate N-Heterocyclic Carbenes. Organometallics 2019, 38, 4133-4146.

(25) For other advances in catalyst design, see: (a) Hauser, P. M.; Hunger, M.; Buchmeiser, M. R. Silica-Supported Molybdenum Alkylidyne N-Heterocyclic Carbene Catalysts: Relevance of Site Isolation to Catalytic Performance. ChemCatChem 2018, 10, 18291834. (b) Koy, M.; Elser, I.; Meisner, J.; Frey, W.; Wurst, K.; Kästner, J.; Buchmeiser, M. R. High Oxidation State Molybdenum NHeterocyclic Carbene Alkylidyne Complexes: Synthesis, Mechanistic Studies, and Reactivity. Chem. - Eur. J. 2017, 23, 15484-15490. (c) Bai, W.; Wei, W.; Sung, H. H. Y.; Williams, I. D.; Lin, Z.; Jia, G. Syntheses of $\operatorname{Re}(\mathrm{V})$ Alkylidyne Complexes and Ligand Effect on the Reactivity of $\operatorname{Re}(\mathrm{V})$ Alkylidyne Complexes toward Alkynes. Organometallics 2018, 37, 559-569. (d) Estes, P. D.; Bittner, C.; Arias, O.; Casey, M.; Fedorov, A.; Tamm, M.; Copéret, C. Alkyne Metathesis with Silica-Supported and Molecular Catalysts at Parts-per-Million Loadings. Angew. Chem., Int. Ed. 2016, 55, 13960-13964.

(26) For inspiring precedent on the use of related ligand platforms, see: (a) Kanady, J. S.; Mendoza-Cortes, J. L.; Tsui, E. Y.; Nielsen, R. J.; Goddard, W. A.; Agapie, T. Oxygen Atom Transfer and Oxidative Water Incorporation in Cuboidal $\mathrm{Mn}_{3} \mathrm{MO}_{\mathrm{n}}$ Complexes Based on Synthetic, isotope Labeling, and Computational Studies. J. Am. Chem. Soc. 2013, 135, 1073-1082. (b) Tsui, E. Y.; Day, M. W.; Agapie, T. Trinuclear Copper: Synthesis and Magnetostructural Characterizatioin of Complexes Supported by a Hexapyridyl 1,3,5-Triarylbenzene Ligand. Angew. Chem., Int. Ed. 2011, 50, 1668-1672.

(27) Feng, X.; Wu, J.; Enkelmann, V.; Müllen, K. Hexa-perihexabenzocoronenes by Efficient Oxidative Cyclodehydrogenation. The Role of the Oligophenylene Precursors. Org. Lett. 2006, 8, 11451148.

(28) The X-ray structures of compounds $8 \mathbf{a}, \mathbf{1 1} \mathbf{b}, \mathbf{1 1} \mathbf{c}, \mathbf{1 5 b}$, and 1,2bis(2,6-dimethylphenyl)ethyne (formed as a byproduct during the preparation of $\mathbf{1 4 b}$ ) are included in the Supporting Information.

(29) (a) Elmorsy, S. S.; Pelter, A.; Smith, K. The Direct Production of Tri- and Hexa-Substituted Benzenes from Ketones under Mild Conditions. Tetrahedron Lett. 1991, 32, 4175-4176. (b) Trawny, D.; Quennet, M.; Rades, N.; Lentz, D.; Paulus, B.; Reissig, H.-U. Syntheses, Structures and Conformational Dynamics of 1,3,5-Tris(3"-ethynylbiphenyl-2'-yl)benzene Derivatives. Eur. J. Org. Chem. 2015, 2015, 4667-4674.

(30) The reaction can be performed at dry ice temperature, but the yield is lower (ca. $40 \%$ ) due to the formation of isomers that result from scrambling of the lithiated sites.

(31) The $\mathrm{MeO}-$ substituents favor scrambling at the stage of the organolithium intermediate, which results in the formation of isomers that are difficult to separate; for details, see the Supporting Information.

(32) The Lee group relied on salt metathesis to form their podand complexes. The two reported examples were obtained in modest yields of $30 \%$ and $50 \%$; see ref 2 .

(33) The Lee group had to use benzylpotassium for the deprotonation of the trisilanole; see ref 2 .

(34) Zhang, W.; Lu, Y.; Moore, J. S. Preparation of a Trisamidomolybdenum(VI) Propylidyne Complex. Org. Synth. 2007, 84, 163-176.

(35) In the case of $14 b$, the crude product contains complex $15 \mathrm{~b}(\mathrm{Ar}$ $\left.=2,6-(\mathrm{Me}){ }_{2} \mathrm{C}_{6} \mathrm{H}_{3}\right)$ and 1,2-bis(2,6-dimethylphenyl)ethyne as byproducts, the formation of which is not entirely clear. These compounds can be removed by careful recrystallization, and their structure was secured by X-ray diffraction; see the Supporting Information.

(36) von Kugelgen, S.; Piskun, I.; Griffin, J. H.; Eckdahl, C. T.; Jarenwattananon, N. N.; Fischer, F. R. Templated Synthesis of EndFunctionalized Graphene Nanoribbons through Living Ring-Opening Alkyne Metathesis Polymerization. J. Am. Chem. Soc. 2019, 141, 11050-11058.

(37) The ${ }^{95}$ Mo NMR signal $\left(\delta_{\mathrm{Mo}}=118 \mathrm{ppm}\right)$ of $\mathbf{1 6}$ is broad (see the Supporting Information), in line with the lower symmetry of the complex that causes faster quadrupolar relaxation. The shift is considerably closer to that of the catalytically incompetent complex $\left[(t \mathrm{BuO})_{3} \mathrm{Mo} \equiv \mathrm{CAr}\right]\left(14 \mathrm{a}, \mathrm{Ar}=p-\mathrm{MeOC}_{6} \mathrm{H}_{4}\right)\left(\delta_{\mathrm{Mo}}=79.6 \mathrm{ppm}\right)$ than to that of the canopy catalysts with tripodal silanolate ligands (359$434 \mathrm{ppm})$.

(38) Fürstner, A.; Seidel, G. Ring-closing Metathesis of Functinalized Acetylene Derivatives: A New Entry into Cycloalkynes. Angew. Chem., Int. Ed. 1998, 37, 1734-1736.

(39) For reviews, see: (a) Neel, A. J.; Hilton, M. J.; Sigman, M. S.; Toste, F. D. Exploiting Non-Covalent $\pi$-Interactions for Catalyst Design. Nature 2017, 543, 637-646. (b) Meyer, E. A.; Castellano, R. K.; Diederich, F. Interactions with Aromatic Rings in Chemical and Biological Recognition. Angew. Chem., Int. Ed. 2003, 42, 1210-1250.

(40) The ortho-benzylidyne protons of $[2 \mathrm{a}]_{2}\left(\delta_{\mathrm{H}}\left(\left[\mathrm{D}_{8}\right]\right.\right.$-toluene $)=$ $6.06(\mathrm{~d}), 5.49 \mathrm{ppm}(\mathrm{d})$, ref 4$)$ and $[1 \mathrm{a}]_{2}\left(\delta_{\mathrm{H}}=5.91,4.93 \mathrm{ppm}\right)$ are strongly shielded. The X-ray structure of $[\mathbf{2 a}]_{2}$ (Figure 4 ) shows that these protons reside in the anisotropy cone of the adjacent phenyl ring. Therefore, it is likely that a similar effect and hence a similar overall arrangement is present in $[\mathbf{1 a}]_{2}$. We like to emphasize, however, that aggregation via reversible covalent cross-linking in $[\mathbf{1 a}]_{2}$ cannot be rigorously excluded as long as no $\mathrm{X}$-ray structure is available.

(41) This anticipation was also based on the fact that complex $\left[\left(\mathrm{Ph}_{3} \mathrm{SiO}\right)_{3} \mathrm{Mo} \equiv \mathrm{CAr}\right]\left(\mathbf{2 b}, \mathrm{Ar}=2,6-(\mathrm{Me})_{2} \mathrm{C}_{6} \mathrm{H}_{3}\right)$ featuring a 2,6disubstituted phenyl ring in lieu of the $p$-methoxyphenyl group of $\mathbf{2 a}$ is monomeric in the solid state (see ref 4) as well as in solution (DOSY; see the Supporting Information).

(42) A complex prepared by the Lee group carrying a mesityl group on the alkylidyne is monomeric (but failed to initiate the alkyne metathesis model reaction chosen by this team); see ref 2 .

(43) The alkylidyne of the adduct $[\mathbf{1 a} \cdot \mathrm{MeCN}]$, however, shows a significant kink $\left(161.4(2)^{\circ}\right)$; cf. ref 1 .

(44) For weak bonding between the metal and a basal phenyl ring in tripodal uranium complexes, see: (a) Bart, S. C.; Heinemann, F.; Anthon, C.; Hauser, C.; Meyer, K. A New Tripodal Ligand System with Steric and Electronic Modularity for Uranium Coordination Chemistry. Inorg. Chem. 2009, 48, 9419-9426. (b) La Pierre, H. S.; Kameo, H.; Halter, D. P.; Heinemann, F. W.; Meyer, K. Coordination and Redox Isomerization in the Reduction of a Uranium(III) Monoarene Complex. Angew. Chem., Int. Ed. 2014, 53, 7154-7157.

(45) (a) Malito, J. Molybdenum-95 NMR Spectroscopy. Annu. Rep. NMR Spectrosc. 1996, 33, 151-206. (b) Mann, B. E. The Cinderella Nuclei. Annu. Rep. NMR Spectrosc. 1991, 23, 141-207.

(46) Young, C. G.; Kober, E. M.; Enemark, J. H. ${ }^{95} \mathrm{Mo}$ and ${ }^{183} \mathrm{~W}$ NMR Studies of Triply Bonded Dinuclear M(III) and Related M $\equiv \mathrm{C}$ $(\mathrm{M}=\mathrm{Mo}$ or $\mathrm{W})$ Complexes. Polyhedron 1987, 6, 255-259.

(47) The extremely low-field ${ }^{95} \mathrm{Mo}$ resonances of the alkylidynes bearing alkyl groups as ancillary ligands reported in ref 46

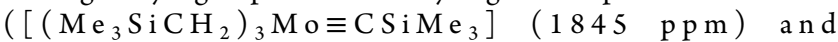
$\left.\left[\left(\mathrm{Me}_{3} \mathrm{CCH}_{2}\right)_{3} \mathrm{Mo} \equiv \mathrm{CCMe}_{3}\right](1400 \mathrm{ppm})\right)$ are puzzling and should be rerecorded.

(48) For a detailed discussion, see: Petrakis, L. Quadrupolar Relaxation of Aluminum-27 Nuclear Magnetic Resonance in Aluminum Alkyls. J. Phys. Chem. 1968, 72, 4182-4188.

(49) The same effect was recorded for If comprising $-\mathrm{SiMe}_{2}-$ linkers $\left(\delta_{\mathrm{Mo}}=422 \mathrm{ppm}\right)$, which also resonates upfield from its otherwise identical sibling 1e with $-\mathrm{SiPh}_{2}-$ bridges $\left(\delta_{\mathrm{Mo}}=434 \mathrm{ppm}\right)$.

(50) (a) Bohmann, J. A.; Weinhold, F.; Farrar, T. C. Natural Chemical Shielding Analysis of Nuclear Magnetic Resonance Shielding Tensors from Gauge-including Atomic Orbital Calculations. J. Chem. Phys. 1997, 107, 1173-1184. (b) Autschbach, J. Analyzing NMR Shielding Tensors Calculated with Two-component Relativistic Methods using Sspin-free Localized Molecular Orbitals. J. Chem. Phys. 2008, 128, 164112. (c) Widdifield, C. M.; Schurko, R. Understanding Chemical Shielding Tensors using Group Theory, MO Analysis, and Modern Density-Functional Theory. Concepts Magn. Reson., Part A 2009, 34A, 91-123. (d) Kaupp, M. Interpretation of NMR Chemical Shifts. In Calculation of NMR and EPR Parameters; Kaupp, M., Bühl, M., Malkin, V. G., Eds.; Wiley-VCH: Weinheim, Germany, 2004; pp 293-306. 
(51) Gordon, C. P.; Raynaud, C.; Andersen, R. A.; Copéret, C.; Eisenstein, O. Carbon-13 NMR Chemical Shifts: A Descriptor for Electronic Structure and Reactivity of Organometallic Compounds. Acc. Chem. Res. 2019, 52, 2278-2289.

(52) For CST analyses of metal alkylidenes and carbenes, see: (a) Blanc, F.; Basset, J.-M.; Copéret, C.; Sinha, A.; Tonzetich, Z. J.; Schrock, R. R.; Solans-Monfort, X.; Clot, E.; Eisenstein, O.; Lesage, A.; Emsley, L. Dynamics of Silica-Supported Catalysts Determined by Combining Solid-State NMR Spectroscopy and DFT Calculations. J. Am. Chem. Soc. 2008, 130, 5886-5900. (b) Halbert, S.; Copéret, C.; Raynaud, C.; Eisenstein, O. Elucidating the Link between NMR Chemical Shifts and Electronic Structure in $\mathrm{d}^{0}$ Olefin Metathesis Catalysts. J. Am. Chem. Soc. 2016, 138, 2261-2272. (c) Yamamoto, K.; Gordon, C. P.; Liao, W.-C.; Copéret, C.; Raynaud, C.; Eisenstein, O. Orbital Analysis of Carbon-13 Chemical Shift Tensors Reveals Patterns to Distinguish Fischer and Schrock Carbenes. Angew. Chem., Int. Ed. 2017, 56, 10127-10131. (d) Biberger, T.; Gordon, C. P.; Leutzsch, M.; Peil, S.; Guthertz, A.; Copéret, C.; Fürstner, A. Alkyne gem-Hydrogenation: Formation of Pianostool Ruthenium Carbene Complexes and Analysis of Their Chemical Character. Angew. Chem., Int. Ed. 2019, 58, 8845-8850.

(53) (a) Suresh, C. H.; Frenking, G. 1,3-Metal-Carbon Bonding and Alkyne Metathesis: DFT Investigations on Model Complexes of Group 4, 5, and 6 Transition Metals. Organometallics 2012, 31, 71717180. (b) Zhu, J.; Jia, G.; Lin, Z. Theoretical Investigation of Alkyne Metathesis Catalyzed by W/Mo Alkylidyne Complexes. Organometallics 2006, 25, 1812-1819.

(54) Computations suggest that the direct formation of a metallatetrahedrane from a molybdenum alkylidyne and an alkyne substrate is symmetry-forbidden. Rather, it is thought to be a derivative of a metallacyclobutadiene precursor; see ref 58 .

(55) Sancho, J.; Schrock, R. R. Acetylene Metathesis by Tungsten(VI) Alkylidyne Complexes. J. Mol. Catal. 1982, 15, 75-79.

(56) Churchill, M. R.; Fettinger, J. C.; McCullough, L. G.; Schrock, R. R. Transformation of a Tungstenacyclobutadiene Complex into a Nonfluxional $\eta^{3}$-Cyclopropenyl Complex by Addition of a Donor Ligand. The X-ray Structure of $\mathrm{W}\left(\eta^{5}-\mathrm{C}_{5} \mathrm{H}_{5}\right)\left[\mathrm{C}_{3}\left(\mathrm{CMe}_{3}\right)_{2} \mathrm{Me}\right]\left(\mathrm{PMe}_{3}\right)$ $\mathrm{Cl}_{2}$. J. Am. Chem. Soc. 1984, 106, 3356-3357.

(57) Schrock, R. R.; Murdzek, J. S.; Freudenberger, J. H.; Churchill, M. R.; Ziller, J. W. Preparation of Molybdenum and Tungsten Neopentylidyne Complexes of the Type $\mathrm{M}\left(\mathrm{CCMe}_{3}\right)\left(\mathrm{O}_{2} \mathrm{CR}\right)_{3}$, Their Reactions with Acetylenes, and the X-ray Structure of the $\eta^{3}$ Cyclopropenyl Complex $\mathrm{W}\left[\mathrm{C}_{3}\left(\mathrm{CMe}_{3}\right) \mathrm{Et}_{2}\right]\left(\mathrm{O}_{2} \mathrm{CCH}_{3}\right)_{3}$. Organometallics 1986, 5, 25-33.

(58) Woo, T.; Folga, E.; Ziegler, T. Density Functional Study of Acetylene Metathesis Catalyzed by High Oxidation State Molybdenum and Tungsten Carbyne Complexes. Organometallics 1993, 12, 1289-1298.

(59) Lin, Z.; Hall, M. B. Stabilities of Metallacyclobutadiene and Metallatetrahedrane Complexes. Organometallics 1994, 13, 28782884.

(60) Schrock, R. R. High-Oxidation-State Molybdenum and Tungsten Alkylidyne Complexes. Acc. Chem. Res. 1986, 19, 342-348.

(61) At $60{ }^{\circ} \mathrm{C}$ with added MS $5 \AA$, the fast rates make a clear ranking difficult.

(62) Meng, Z.; Fürstner, A. Total Synthesis of (-)-Sinulariadiolide. A Transannular Approach. J. Am. Chem. Soc. 2019, 141, 805-809.

(63) Chen, P.; Zhang, L.; Xue, Z.-L.; Wu, Y.-D.; Zhang, X. Density Functional Theory Study of the Reaction between $\mathrm{d}^{0}$ Tungsten Alkylidyne Complexes and $\mathrm{H}_{2} \mathrm{O}$ : Addition versus Hydrolysis. Inorg. Chem. 2017, 56, 7111-7119.

(64) Fürstner, A.; Mathes, C.; Lehmann, C. W. $\mathrm{Mo}[\mathrm{N}(t \mathrm{Bu})(\mathrm{Ar})]_{3}$ Complexes as Catalyst Precursors: In Situ Activation and Application to Metathesis Reactions of Alkynes and Diynes. J. Am. Chem. Soc. 1999, 121, 9453-9454.

(65) For pertinent examples, see: (a) Wölfl, B.; Mata, G.; Fürstner, A. Total Synthesis of Callyspongiolide, Part 2: The Ynoate Metathesis/cis-Reduction Strategy. Chem. - Eur. J. 2019, 25, 255259. (b) Schaubach, S.; Michigami, K.; Fürstner, A. Hydroxyl-Assisted
trans-Reduction of 1,3-Enynes: Applicatio to the Foraml Syntehis of (+)-Aspicillin. Synthesis 2016, 49, 202-208.

(66) Fürstner, A.; Guth, O.; Rumbo, A.; Seidel, G. Ring Closing Alkyne Metathesis. Comparative Investigation of Two Different Catalyst Systems and Application to the Stereoselective Synthesis of Olfactory Lactones, Azamacrolides, and the Macrocyclic Perimeter of the Marine Alkaloid Nakadomarin A. J. Am. Chem. Soc. 1999, 121, 11108-11113.

(67) (a) Fürstner, A.; Mathes, C.; Lehmann, C. W. Alkyne Metathesis: Development of a Novel Molybdenum-Based Catalyst System and its Application to the Total Synthesis of Epothilone A and C. Chem. - Eur. J. 2001, 7, 5299-5315. (b) Fürstner, A.; Mathes, C.; Grela, K. Concise Total Syntheses of Epothilone A and C Based on Alkyne Metathesis. Chem. Commun. 2001, 1057-1059.

(68) (a) Fürstner, A.; Larionov, O.; Flügge, S. What is Amphidinolide V? Report on a Likely Conquest. Angew. Chem., Int. Ed. 2007, 46, 5545-5548. (b) Fürstner, A.; Flügge, S.; Larionov, O.; Takahashi, Y.; Kubota, T.; Kobayashi, J. Total Synthesis and Biological Evaluation of Amphidinolide V and Analogues. Chem. Eur. J. 2009, 15, 4011-4029.

(69) (a) Valot, G.; Regens, C. S.; O'Malley, D. P.; Godineau, E.; Takikawa, H.; Fürstner, A. Total Synthesis of Amphidinolide F. Angew. Chem., Int. Ed. 2013, 52, 9534-9538. (b) Valot, G.; Mailhol, D.; Regens, C. S.; O’Malley, D. P.; Godineau, E.; Takikawa, H.; Philipps, P.; Fürstner, A. Concise Total Syntheses of Amphidinolide C and F. Chem. - Eur. J. 2015, 21, 2398-2408.

(70) For other examples, see the following and literature cited therein: (a) Yu, M.; Wang, C.; Kyle, A. f.; Jakubec, P.; Dixon, D. J.; Schrock, R. R.; Hoveyda, A. H. Synthesis of Macrocyclic Natural Products by Catalyst-Controlled Stereoselective Ring-Closing Metathesis. Nature 2011, 479, 88-93. (b) Mu, Y.; Nguyen, T. T.; Koh, M. J.; Schrock, R. R.; Hoveyda, A. H. E- and Z-, Di- and Tri-Substituted Alkenyl Nitriles through Catalytic Cross-Metathesis. Nat. Chem. 2019, 11, 478-487. For a general treatise, see: (c) Catalysis Without Precious Metals; Bullock, R. M., Ed.; Wiley-VCH: Weinheim, Germany, 2010. 